\title{
Guidance for the Management of Patients with Vascular Disease or Cardiovascular Risk Factors and COVID-19: Position Paper from VAS-European Independent Foundation in Angiology/Vascular Medicine
}

Grigoris T. Gerotziafas ${ }^{1,20}$ Mariella Catalano ${ }^{3} \quad$ Mary-Paula Colgan ${ }^{4}$ Zsolt Pecsvarady ${ }^{5}$ Jean Claude Wautrecht ${ }^{6}$ Bahare Fazeli ${ }^{7}$ Dan-Mircea Olinic ${ }^{8}$ Katalin Farkas ${ }^{9}$ Ismail Elalamy I,2,10 $^{10}$ Anna Falanga ${ }^{11}$ Jawed Fareed ${ }^{12}$ Chryssa Papageorgiou ${ }^{13}$ Rosella S. Arellano ${ }^{14}$ Petros Agathagelou ${ }^{15}$ Darco Antic $^{16}$ Luciana Auad $^{17}$ Ljiljana Banfic ${ }^{18}$ John R. Bartolomew ${ }^{19}$ Bela Benczur ${ }^{20}$ Melissa B. Bernardo ${ }^{14}$ Francesco Boccardo ${ }^{21}$ Renate Cifkova ${ }^{22}$ Benilde Cosmi ${ }^{23}$ Sergio De Marchi ${ }^{24}$ Evangelos Dimakakos ${ }^{25}$ Meletios A. Dimopoulos ${ }^{26,27}$ Gabriel Dimitrov ${ }^{3}$ Isabelle Durand-Zaleski ${ }^{28}$ Michael Edmonds ${ }^{29}$ Essam Abo El Nazar ${ }^{30}$ Dilek Erer $^{31}$ Omar L. Esponda ${ }^{32}$ Paolo Gresele ${ }^{33}$ Michael Gschwandtner ${ }^{34}$ Yongquan $\mathrm{Gu}^{35}$ Mónica Heinzmann ${ }^{17}$ Naomi M. Hamburg ${ }^{36}$ Amer Hamadé ${ }^{37}$ Noor-Ahmed Jatoi ${ }^{38}$ Oguz Karahan ${ }^{39}$ Debora Karetova $^{40}$ Thomas Karplus ${ }^{41}$ Peter Klein-Weigel ${ }^{42}$ Endre Kolossvary ${ }^{9}$ Matija Kozak ${ }^{43}$ Eleftheria Lefkou ${ }^{44}$ Gianfranco Lessiani ${ }^{45}$ Aaron Liew ${ }^{46}$ Antonella Marcoccia ${ }^{47}$ Peter Marshang ${ }^{48}$ George Marakomichelakis ${ }^{49}$ jiri Matuska ${ }^{50}$ Luc Moraglia ${ }^{51}$ Sergio Pillon ${ }^{52}$ Pavel Poredos ${ }^{53}$ Manlio Prior ${ }^{54}$ David Raymund K. Salvador ${ }^{14}$ Oliver Schlager ${ }^{55}$ Gerit Schernthaner ${ }^{55}$ Alexander Sieron ${ }^{56,57}$ Jonas Spaak ${ }^{58}$ Alex Spyropoulos ${ }^{59}$ Muriel Sprynger ${ }^{60}$ Dusan Suput ${ }^{61}$ Agata Stanek ${ }^{62}$ Viera Stvrtinova ${ }^{63}$ Andrzej Szuba ${ }^{64}$ Alfonso Tafur ${ }^{65}$ Patrick Vandreden ${ }^{2}$ Panagiotis E. Vardas ${ }^{66}$ Dragan Vasic $^{67}$ Miikka Vikkula ${ }^{68}$ Paul Wennberg ${ }^{69}$ Zhenguo Zhai ${ }^{70,71}$ Scientific Reviewer Committee*

${ }^{1}$ Hematology and Thrombosis Center, Hôpital Tenon, Hôpitaux Universitaires de l'Est Parisien, Assistance Publique Hôpitaux de Paris, Faculté de Médecine, Sorbonne Université, Paris, France

2 Research Group Cancer, Haemostasis and Angiogenesis," INSERM U938, Centre de Recherche Saint-Antoine, Institut Universitaire de Cancérologie, Faculty of Medicine, Sorbonne University, Paris, France

3 Research Center on Vascular Disease \& Angiology Unit, Department of Biomedical Science, L Sacco Hospital, University of Milan, Milan, Italy

4 Department of Vascular Surgery, St. James's Hospital/Trinity College Dublin, Dublin, Ireland

${ }^{5}$ Department of Vascular Medicine, Flor Ferenc Teaching Hospital, Kistarcsa, Hungary

${ }^{6}$ Service de Pathologie Vasculaire, Hôpital ERASME, Université Libre de Bruxelle, Brussels, Belgium

Scientific Reviewer Committee Members: Behnood Bikdeli, Yutao Guo, Job Harenberg, Yu Hu, Gregory Y. H. Lip, Vanessa Roldan.

Address for correspondence Grigoris T. Gerotziafas, MD, PhD, VAS Board, VAS-European Independent Foundation in Angiology/Vascular Medicine (www.vas-int.net). INSERM U938 Bâtiment Kourilsky, 34 rue Crozatier, Hôpital Saint Antoine, Paris, Cedex 75012, France (e-mail: grigorios.gerotziafas@inserm.fr).

${ }^{7}$ Immunology Department, Avicenna (Bu-Ali) Research Institute, Mashhad University of Medical Sciences, Iran

8 Medical Clinic No. 1, University of Medicine and Pharmacy, ClujNapoca, Romania

${ }^{9}$ Department of Angiology, St. Imre University Teaching Hospital, Budapest, Hungary

${ }^{10}$ Department of Obstetrics and Gynecology, I.M.Sechenov First Moscow State Medical University (Sechenov University), Moscow, Russia

${ }^{11}$ Department of Immunohematology and Transfusion Medicine, \& the Thrombosis and Hemostasis Center, Hospital Papa Giovanni XXIII, Bergamo, Italy

${ }^{12}$ Department of Pathology, Loyola University Medical Center, Maywood, Illinois, United States

(c) 2020. Thieme. All rights reserved. Georg Thieme Verlag KG,

Rüdigerstraße 14,

70469 Stuttgart, Germany
DOI https://doi.org/ 10.1055/s-0040-1715798. ISSN 0340-6245. accepted after revision July 23,2020 
${ }^{13}$ Service Anesthésie, Réanimation et Médecine Périopératoire, Hôpital Tenon, Hôpitaux Universitaires de l’Est Parisien, Assistance Publique Hôpitaux de Paris, Faculté de médecine, Sorbonne Université, Paris, France

14 Philippine Society of Vascular Medicine, Manila, Philippine

${ }^{15}$ Department of Inrterventional Cardiology, American Heart Institute of Cyprus, Nicosia, Cyprus,

${ }^{16}$ Clinic for Hematology, Clinical Center of Serbia, Faculty of Medicine, University of Belgrade, Belgrade, Serbia

${ }^{17}$ Medicina Vascular, Sanatorio Allende Córdoba, Ciencias Médicas, Universidad Católica de Córdoba, Argentina

18 University Hospital Center, School of Medicine University of Zagreb, Croatia

${ }^{19}$ Cleveland Clinic, Cleveland, Ohio, United States

${ }^{20}$ Balassa Janos County Hospital, University Medical School, Szeged, Hungary

${ }^{21}$ Department of Cardio-Thoracic-Vascular and Endovascular Surgery, Unit of Lymphatic Surgery, IRCCS S. Martino Hospital, University of Genoa, Italy

${ }^{22}$ Department of Preventive Cardiology, Thomayer Teaching Hospital, Prague, Czech Republic

${ }^{23}$ Angiology and Blood Coagulation, Department of Specialty, Diagnostic and Experimental Medicine, S. Orsola-Malpighi University Hospital, University of Bologna, Bologna, Italy

${ }^{24}$ Angiology Unit, Cardiovascular and Thoracic and Medicine Department, Verona University Hospital, Verona, Italy

${ }^{25}$ Vascular Unit of 3rd Department of Internal Medicine, Sotiria Hospital, National and Kapodistrian University of Athens, Athens, Greece

26 Hellenic Society of Hematology, Athens, Greece

27 Department of Clinical Therapeutics, School of Medicine, National and Kapodistrian University of Athens, Athens, Greece

28 Université de Paris, CRESS, INSERM, INRA, URCECo, AP-HP, Hôpital de l'Hôtel Dieu, Paris, France

${ }^{29}$ Diabetic Foot Clinic, King's College Hospital, London, United Kingdom

${ }^{30}$ Departement of Surgery, Ministry of Health, Saudi Arabia

${ }^{31}$ Department of Cardiovascular Surgery, Faculty of Medicine, Gazi University, Besevler/Ankara, Turkey

32 Internal Medicine Department, Hospital Perea, Mayaguez, Puerto Rico, United States

${ }^{33}$ Section of Internal and Cardiovascular Medicine, Department of Medicine, -University of Perugia, Perugia, Italy

${ }^{34}$ MedizinischeUniverstiät Wien, Universitätsklinik für Innere Medizin II, Klinische Abteilung für Angiologie, Vienna, Austria

${ }^{35}$ Department of Vascular Surgery, Xuanwu Hospital, Capital Medical University, Beijing China

${ }^{36}$ The Whitaker Cardiovascular Institute Department of Medicine Boston University School of Medicine, Boston, Massachusetts, United States

37Vascular Medicine Unit, Internal Medicine Department, King Fahad University Hospital, Imam Abdulrahman Bin Faisal University, Dammam, Saudi Arabia

${ }^{38}$ Department Vascular Medicine, Mulhouse Hospital Center, Mulhouse, France

${ }^{39}$ Department of Cardiovascular Surgery, Medical School of Alaaddin Keykubat University, Alanya/Antalya, Turkey

${ }^{40}$ Second Department of Medicine, Department of Cardiovascular Medicine, Charles University in Prague, Prague, Czech Republic

${ }^{41}$ Department of Vascular Medicine, Concord Repatriation General Hospital, Sydney, Australia

42 Klinik für Angiologie, Zentrum für Innere Medizin II, Ernst von Bergmann Klinikum, Potsdam, Germany

43 Department for Vascular Diseases, Medical Faculty of Ljubljana, University Medical Center Ljubljana, Ljubljana, Slovenia

Thromb Haemost 2020;120:1597-1628
${ }^{44}$ Board member of the Institute for the Study and Education on Thrombosis and Antithrombotic Therapy, Athens, Greece

${ }^{45}$ Angiology Unit, Internal Medicine Department., Città Sant' Angelo Hospital, AUSL 03, Pescara, Italy

46 Portiuncula University Hospital, Soalta University Health Care Group, National University of Ireland Galway (NUIG), Galway, Ireland

${ }^{47}$ Unità di Medicina Vascolare e Autoimmunità, CRIIS-Centro di riferimento interdisciplinare per la Sclerosi Sistemica, Rome, Italy

${ }^{48}$ Department of Internal Medicine, Central Hospital of Bolzano, Bolzano, Italy

${ }^{49}$ Angiology Unit, Evangelismos General Hospital, Athens, Greece

50 MATMED s.r.o., Private Angiology Facility, Hodonin, Czech Republic

${ }^{51}$ Angiologie Centre Cours du Médoc, Médecine Vasculaire Travail, Bordeaux, France

${ }^{52}$ UOSD Angiology, San Camillo-Forlanini Hospital, National Health Institute ISS, Rome, Italy

53 Medical Association of Slovenia and SMA, Slovenia Academic Research Centre, Slovenian Medical Academy, Ljubljana, Slovenia

${ }^{54}$ Angiology Unit, Azienda Ospedaliera Universitaria Integrata di Verona, Verona, Italy

${ }^{55}$ Division of Angiology, Department of Internal Medicine 2, Medical University of Vienna, Vienna, Austria

56 Department of Internal Medicine, Angiology and Physical Medicine, Medical University of Silesia, Katowice, Poland

57 Specialist Hospital, Bytom, Jan Długosz University in Częstochowa, Częstochowa, Poland

${ }^{58}$ Department of Clinical Sciences, Danderyd Hospital, Division of Cardiovascular Medicine, Karolinska Institutet, Stockholm, Stockholm County, Sweden

${ }^{59}$ Department of Medicine, Anticoagulation and Clinical Thrombosis Services, Northwell Health at Lenox Hill Hospital, The Donald and Barbara Zucker School of Medicine at Hofstra/Northwell, The Feinstein Institute for Medical Research, New York, New York, United States

${ }^{60}$ Cardiology Department, University Hospital Sart Tilman, Liege, Belgium

${ }^{61}$ Center for Clinical Physiology, Faculty of Medicine, University of Ljubljana, Ljubljana, Slovenia

62 Department of Internal Medicine, Angiology and Physical Medicine, Faculty of Medical Sciences in Zabrze, Medical University of Silesia, Bytom, Poland

63 Faculty of Medicine, Comenius University, Bratislava, Slovak Republic

${ }^{64}$ Department of Angiology, Hypertension and Diabetology, Wroclaw Medical University, Wroclaw, Poland

${ }^{65}$ Vascular Medicine University of Chicago, Northshore Cardiovascular Institute, Skokie, Illinois, US Army

${ }^{66}$ Medical School of Crete, University of Crete and Heart Sector, Hellenic Healthcare Group, Athens, Greece

${ }^{67}$ Department of Noninvasive vascular laboratory, Clinic of Vascular and Endovascular Surgery, Clinical Centre of Serbia, Belgrade, Serbia

${ }^{68}$ Human Molecular Genetics, de Duve Institute, University of Louvain, Brussels, Belgium

${ }^{69}$ Department of Cardiovascular Medicine, Gonda Vascular Center, Mayo Clinic, Rochester, Minnesota, United States

70 Department of Pulmonary and Critical Care Medicine, Center of Respiratory Medicine, China-Japan Friendship Hospital, Peking University Health Science Center, Capital Medical University, Beijing, China

71 Institute of Respiratory Medicine, Chinese Academy of Medical Sciences, Beijing, China 


Abstract
Keywords
- COVID-19
- cardiovascular
disease
- peripheral artery
disease
- deep vein thrombosis
- antithrombotic
- antiplatelets
- anticoagulants
- low-molecular-weight
- DOAC

COVID-19 is also manifested with hypercoagulability, pulmonary intravascular coagulation, microangiopathy, and venous thromboembolism (VTE) or arterial thrombosis. Predisposing risk factors to severe COVID-19 are male sex, underlying cardiovascular disease, or cardiovascular risk factors including noncontrolled diabetes mellitus or arterial hypertension, obesity, and advanced age. The VAS-European Independent Foundation in Angiology/Vascular Medicine draws attention to patients with vascular disease (VD) and presents an integral strategy for the management of patients with VD or cardiovascular risk factors (VD-CVR) and COVID-19. VAS recommends (1) a COVID19-oriented primary health care network for patients with VD-CVR for identification of patients with VD-CVR in the community and patients' education for disease symptoms, use of eHealth technology, adherence to the antithrombotic and vascular regulating treatments, and (2) close medical follow-up for efficacious control of VD progression and prompt application of physical and social distancing measures in case of new epidemic waves. For patients with VD-CVR who receive home treatment for COVID-19, VAS recommends assessment for (1) disease worsening risk and prioritized hospitalization of those at high risk and (2) VTE risk assessment and thromboprophylaxis with rivaroxaban, betrixaban, or low-molecular-weight heparin (LMWH) for those at high risk. For hospitalized patients with VD-CVR and COVID-19, VAS recommends (1) routine thromboprophylaxis with weight-adjusted intermediate doses of LMWH (unless contraindication); (2) LMWH as the drug of choice over unfractionated heparin or direct oral anticoagulants for the treatment of VTE or hypercoagulability; (3) careful evaluation of the risk for disease worsening and prompt application of targeted antiviral or convalescence treatments; (4) monitoring of D-dimer for optimization of the antithrombotic treatment; and (5) evaluation of the risk of VTE before hospital discharge using the IMPROVE-D-dimer score and prolonged post-discharge thromboprophylaxis with rivaroxaban, betrixaban, or LMWH.

\section{Introduction}

Severe acute respiratory syndrome coronavirus 2 (SARSCoV-2), an enveloped nonsegmented positive-sense RNA virus, causes coronavirus disease 2019 (COVID-19). SARSCoV-2 invades host human cells by binding to the angiotensin-converting enzyme 2 (ACE2) receptor and by means of the transmembrane protease serine 2 (TMPRSS2) and the SARS-CoV-2 main protease (Mpro). ${ }^{1-4}$ COVID-19 is a systemic, potentially severe, and life-threatening disease, triggered by the SARS-CoV-2 infection, which involves both immune and inflammatory responses, endothelial cell dysfunction, complement activation, and a hypercoagulable state. ${ }^{5-9}$

From mid-December 2019, when the first cases of SARSCoV-2 infection were officially declared, to August 2020, more than 26 million cases and 860,000 deaths have been declared worldwide.

In March 2020, the World Health Organization (WHO) officially declared the SARS-CoV-2 infection as a pandemic and classified COVID-19 in three levels of severity: (1) severe illness designated when the patients have fever or suspected respiratory infection, plus one of the following: respiratory rate $>30$ breaths/min, severe respiratory distress, or pulse oximeter oxygen saturation $\leq 93 \%$ on room air; (2) critical illness defined in patients with acute respiratory distress syndrome (ARDS) or sepsis with acute organ dysfunction; and (3) nonsevere type inpatients without any of the above conditions. ${ }^{5}$

While most people with COVID-19 develop only nonsevere illness, usually characterized by fever, cough, myalgias, and breath shortness, approximately 15\% develop severe disease that requires hospitalization and oxygen support and 5\% present critical illness requiring admission to an intensive care unit (ICU). 5,6,10 The mortality rate in patients with critical illness raised up to $50 \%$ at the beginning of the epidemic and progressively dropped to approximately 35 to $45 \%{ }^{11,12}$

Emerging data indicate that SARS-CoV-2 infection is a multifocal disease which implicates the respiratory, cardiovascular, renal, gastrointestinal, and central nervous systems. ${ }^{13-15}$ Hypercoagulability is a frequent hematological alteration in hospitalized patients with COVID-19 and a predictor of disease worsening. Venous thromboembolism (VTE), and particularly pulmonary embolism (PE), is more frequent in hospitalized patients with COVID-19 as compared with patients hospitalized for other acute medical illnesses even when recommended pharmacological thromboprophylaxis is administered. Disseminated intravascular 
coagulation (DIC) may occur in patients with critical illness and is a relevant predictor of death. Immunothrombosis with pulmonary intravascular coagulation (PIC) and vascular occlusion in the microcirculation of the lungs are frequent findings reported in autopsies of patients died from COVID19. Last but not least, patients with COVID-19 are also at increased risk for arterial thrombosis (ischemic stroke, myocardial infarction, limb ischemia). Accordingly, COVID-19 is a systematic disease involving blood coagulation and vessels. Patients with cardiovascular disease (CVD) or cardiovascular risk factors are the most vulnerable for deterioration to severe COVID-19 and critical illness following SARS-CoV19 infection.

CVD-including ischemic stroke, carotid artery disease, coronary artery disease, peripheral artery disease (PAD)-is according to the WHO a pathology of the circulatory system which involves endothelial cell dysfunction. ${ }^{16}$ CVD has an age-standardized prevalence from 5,000 to 9,000 cases per 100,000 persons varying by country. The prevalence of cardiovascular risk factors (i.e., obesity, diabetes mellitus, or arterial hypertension) is even higher. ${ }^{17}$

The term "patients with vascular disease or cardiovascular risk factors" (VD-CVR) refers to patients with a personal history of arteriopathy or arterial thrombosis, including patients with a history of ischemic stroke, carotid artery disease, coronary artery disease, PAD, or arterial thrombosis of rare localization (i.e., mesenteric artery thrombosis) and patients with a history of deep vein thrombosis (DVT), PE, or vein thrombosis of rare localization (i.e., cerebral vein thrombosis, splanchnic vein thrombosis, upper limb thrombosis). Obese individuals (body mass index [BMI] $>30$ ) and patients with diabetes mellitus or arterial hypertension are also included.

Following SARS-CoV-19 infection, patients with VD-CVR are at risk for severe COVID-19 and critical illness, which during the epidemic periods may destabilize the health systems. The guidelines and position papers published so far concern COVID-19 patients in general and focus mainly on the prevention and treatment of VTE and some of them propose therapeutic guidance for DIC.

Facing the magnitude and the duration of the SARS-CoV-2 epidemic and the absence of a specific vaccine, there is an urgent need for an integral and targeted strategy for patients with CVD, aiming the prevention of SARS-CoV-2 infection and the management of the COVID-19 vascular complications which may lead to disease worsening.

The VAS-European Independent Foundation in Angiology/Vascular Medicine responds to this challenge with the present guidance providing (1) the principles for the organization of a primary health care network focused on patients with VD-CVR, (2) the methodology for the identification of patients with vascular disease among patients with COVID-19 and the evaluation of the risk for disease worsening, (3) the necessary information for pharmacological and pharmacodynamic issues of antithrombotic agents and vascular regulating treatments which are potentially influenced by COVID-19 or the associated treatments, (4) the strategies for the management of the hypercoagulable state and the diagnosis and treatment of DIC, and (5) the recommendations for the prevention and treatment of VTE adapted for patients with VD-CVR.

\section{Methods}

We did a literature review by searching in PubMed from January 1 to July 14, 2020 for published studies using the following key words: "COVID-19," or "SARS-CoV-2," or "coronavirus" and "antithrombotic treatment," "arteriopathy," "arterial thrombosis," "autopsy," "blood coagulation," "cardiovascular disease," "cardiovascular risk factors," "contact system," "complement," "disease deterioration," "disseminated intravascular coagulation," "DOAC," "fibrinolysis," "gender," "heparin," "hypercoagulability," "intensive care unit," "LMWH," "mortality," "pathogenesis," "peripheral artery disease," "pulmonary intravascular coagulation," "risk assessment," "risk factors," "thrombosis," "statin," "thrombolysis," and "venous thromboembolism."

We reviewed manuscripts on three servers (https://www. medrxiv.org/, https://www.preprints.org/, and https://www. ssrn.com/index.cfm/en/coronavirus/). The last literature research was performed on July 14, 2020. Relevant articles were screened and analyzed by G.T.G. and M.C. Subsequently, the initial document with the guidelines was formulated by the members of the VAS Board (G.T.G., M.C., M.P.C., Z.P., J.C. W., B.F., D.M.O., K.F.). The initial document was subsequently submitted to the VAS Advisory Board and circulated to all the authors for comments. Recommendations and suggestions were formulated with the unanimous accordance of the ensemble of the authors. Due to the limited clinical experience in patients with COVID-19 and the absence of randomized clinical trials controlling the efficacy and safety of various antithrombotic treatment regimens and the other interventions in the context of COVID-19, the ensemble of the proposed recommendations has a low grade of evidence. This guidance will be updated, and the relevant algorithms will be formulated as soon as new epidemiological evidence and results of ongoing clinical studies will be published. In the meanwhile, the VAS web site (www.vas-int.net) and its links with various national medical societies in relation with the management of patients with VD-CVR will be the key vectors for the implementation of this guidance. At the actual phase of SARS-CoV-2 epidemic and facing the urgent situation produced by the vast wave of patients with COVID-19 worldwide, there are no means for cost evaluation of the interventions proposed by the guidance as well as for the audit to assess the guidance implementation.

\section{Hypercoagulability and Endothelial Activation: Key Elements in Deterioration of COVID-19}

\section{Structural Elements of SARS-CoV-2 and Activation of Endothelial Cells and Coagulation}

SARS-CoV-2 receptor binding occurs via the spike (S) protein (encoded by the structural S gene) which has two subunits: subunit S1 mediates binding and a trimeric S2 stalk mediates 
fusion to the infected cell. The S1 subunit is divided into two domains, the N-terminal domain (S1-NTD) and the C-terminal domain (S1-CTD). These regions mediate binding to a variety of cellular receptors. Endothelial cells of arteries and veins, arterial smooth muscle cells, cardiomyocytes, and type I and type II alveolar epithelial cells in human lung tissue express ACE2 and are targets of SARS-CoV-2 infection spread. ${ }^{18}$ The S1-CTD binds with high affinity to the ACE2 receptor and the TMPRSS2. Cell infection with SARS-CoV-2 requires coexpression of ACE2 and TMPRSS2. Cleavage of the $S$ protein by the TMPRSS2 is necessary for binding of SARSCoV-2 to ACE2. ${ }^{19}$ The TMPRSS2 is abundantly expressed by cells in the lung tissue and makes the respiratory system vulnerable to virus infection. ${ }^{20}$ Following entry to alveolar epithelial cells, components of the SARS-CoV-2 trigger immune response via different pathways, including immunological receptors on and inside immune cells, retinoic acidinducible gene-I (RIG-I)-like receptors (RLRs), toll-like receptors (TLRs), NOD-like receptors (NLRs), and cyclic GMP-AMP synthase (cGAS), which activate intracellular signaling cascades, leading to the secretion of proinflammatory cytokines and chemokines. Additional endogenous adjuvant activity is provided by pyroptotic cell death regulated by the nod-like receptor family, pyrin domain containing 3 (NLRP3) inflammasome activation. The endogenous adjuvant activity following SARS-CoV-2 infection is caused by the direct activation of NLRP3 by the viral protein viroporin protein 3a. Infiltration, accumulation, and activation of defense cells (i.e., neutrophils, monocytes, lymphocytes, macrophages, and dendritic cells) amplify the immune reaction and lead to cytokines secretion. The cytokines interleukin (IL)-1, IL-6, interferon gamma, and tissue necrosis factor $\alpha$ are major effectors of the cytokine storm induced by the SARS-CoV-2.

\section{Activation of Complement in SARS-CoV-2 Infection}

SARS-CoV-2 either directly or through the immune reaction induces activation of the complement system which is a part of the innate immune system. Natural (immunoglobulin $\mathrm{M}$ ) antibodies that recognize viral antigens or neoantigens exposed on damaged host tissues activate the classical pathway. Viral components such as the nuclear protein $(\mathrm{N}$ protein) directly interact with mannose-binding lectin-associated proteases 2 (MASP2) leading to the activation of the mannose-binding lectin pathway. Debris from dying cells in multiple ischemic organs likely shed lipid-anchored membrane complement regulatory proteins (such as DAF and CD59), and lose glycosaminoglycans (GAGs) allowing complement activation by the alternative pathway. Activated complement promotes inflammation. The anaphylatoxins C3a and C5a are likely major contributors to cytokine storm syndrome through their intrinsic proinflammatory activities in leukocyte activation and trafficking, and by synergizing with other innate immune sensors, such as TLRs. C3a and $\mathrm{C} 5 \mathrm{a}$, and direct cell lysis with the assembly of the membrane attack complex C5b-9. Both immunologic and nonimmunologic tissue damage can initiate the kinin formation and the activation of the intrinsic pathway of blood coagulation (for review see Song and FitzGerald ${ }^{21}$ ).

\section{Direct Procoagulant Activity of SARS-CoV-2}

The vascular system is also a target of the virus because TMPRSS2 is expressed by endothelial cells. ${ }^{22}$ Accordingly, endothelial cells at least at the level of lung vasculature are exposed to SARS-CoV-2 infection and are subjects of activation. The TMPRSS2 is the most important, but not the unique, protease that cleaves $S$ protein. Other proteases such as cathepsins and activated factor X (FXa) also effectively cleave the full-length $S$ protein. ${ }^{23}$

SARS-CoV-2 may directly induce activation of coagulation through the highly conserved main proteinase (Mpro)-also known as 3Clpro-that catalyzes the viral polyprotein processing, a necessary procedure for SARS-CoV-2 infection. ${ }^{24}$ According to three-dimensional structure analysis, the active site of the Mpro from SARS-CoV-2 shares structural similarities with the active site of FXa and thrombin and it may activate blood coagulation. Mpro is unique in the virus and not found in the host cells, being a prominent target for the development of antiviral agents. In silico modelization experiments showed that the direct FXa inhibitors apixaban and betrixaban and the direct thrombin inhibitor argatroban are potential inhibitors of the SARS-CoV-2 invasion. ${ }^{25,26}$ Presumably heparins by amplifying antithrombin (AT) activity against FXa and thrombin or a direct binding to these extracellular membrane receptors might also compromise SARS-CoV-2 Mpro pathways. ${ }^{27,28}$

\section{Activation of Blood Coagulation in SARS-CoV-2 Infection}

Platelet activation and contact-system-initiated thrombin generation are involved in the pathogenesis of immunothrombosis in several critical pathological states such as septicemia, bacterial DIC, or ARDS. ${ }^{29}$ Hypercoagulability in patients with COVID-19 is also initiated by activation of the contact system, which is composed of three groups of serine proteinases: (1) plasma prekallikrein (PPK); (2) the clotting factors XII (FXII) and XI (FXI), and (3) the nonenzymatic cofactor "high-molecular-weight kininogen" (HMWK). ${ }^{30}$ Cleavage of free HMWK by plasma kallikrein (PK) releases bradykinin, a potent inflammatory mediator and an activator of the complement and contact system. ${ }^{8}$

The contact system components bind to vascular endothelium, platelets, and neutrophils, with the HMWK serving as a docking site for PPK.

GAGs at the surface of endothelial cells regulate bradykinin generation. HMWK bound to GAGs is "protected" from PK and generation of bradykinin is therefore reduced. Low availability of GAGs (i.e., in the case of endothelial cell activation) results in an increased concentration of free HMWK available for bradykinin generation upon exposure to PK.

Contact system activation leads also to FXII activation (FXIla), which in its turn binds to negatively charged phospholipids and activates FXI triggering the sequential activation of FIX and FX, leading to thrombin generation which amplifies its generation by activating factors V and VIII and platelets that offer procoagulant phospholipids for the formation the intrinsic tenase and prothrombinase. ${ }^{31}$ 
Among the negatively charged surfaces present in blood and vessels (i.e., collagen, cholesterol sulfate, sulfatides, acid phospholipids, fatty acids, and several charged carbohydrates), the polyphosphates (polyP) released by activated platelets appear to play a major role in FXII activation. ${ }^{32}$

An increase of polyP and a decrease of GAG lead to amplification of the thrombin generation process, inflammatory response, and vasoconstriction at the level of lung microcirculation. The enhanced cytokine production during virus infection also stimulates additional procoagulant reactions, with increased tissue factor (TF) expression, a major initiator of the coagulation. The GAGs' availability on endothelial cell membranes and the release of polyP from activated platelets regulate the contact system protein assembly, bradykinin formation, and FXII activation. Thrombin in its turn leads to fibrin formation, activates FVII and FXII, enhances platelet activation, alters fibrinolysis, and is a major mediator of inflammatory reactions. Initiation of a vicious cycle of thrombin generation may lead to consumption of natural coagulation inhibitors (i.e., AT, protein C [PC], and protein S) and to a compensated DIC. Unbalanced activation of endothelial cells either by a direct effect from the SARS-CoV-2 infection or as a result of the inflammatory procedure results in further TF expression.

Neutrophil extracellular traps (NETs) and damage-associated molecular patterns may also be involved in the procoagulant profile in patients with COVID-19. ${ }^{33-35}$ In some cases, the presence of antiphospholipid antibodies that can also induce arterial thrombosis has been reported, but this is a controversial issue. ${ }^{36,37}$

-Fig. 1 summarizes the principal mechanisms triggered by SARS-CoV-2 infection leading to enhanced thrombin generation and pulmonary intravascular coagulation.

\section{Endothelial Cell Activation and Pulmonary Intravascular Coagulopathy in COVID-19}

Emerging data underline the crucial role of endothelial cell activation during SARS-CoV-2 infection, as a direct target of the virus and inflammatory cytokines as well as the main actors in orchestrating a proinflammatory and procoagulant state in COVID-19 patients. $^{38}$ The increased number of circulating endothelial cells in the blood from patients with COVID-19 corroborates the concept of the involvement of endothelial cell activation. ${ }^{39}$ Autopsies in COVID-19

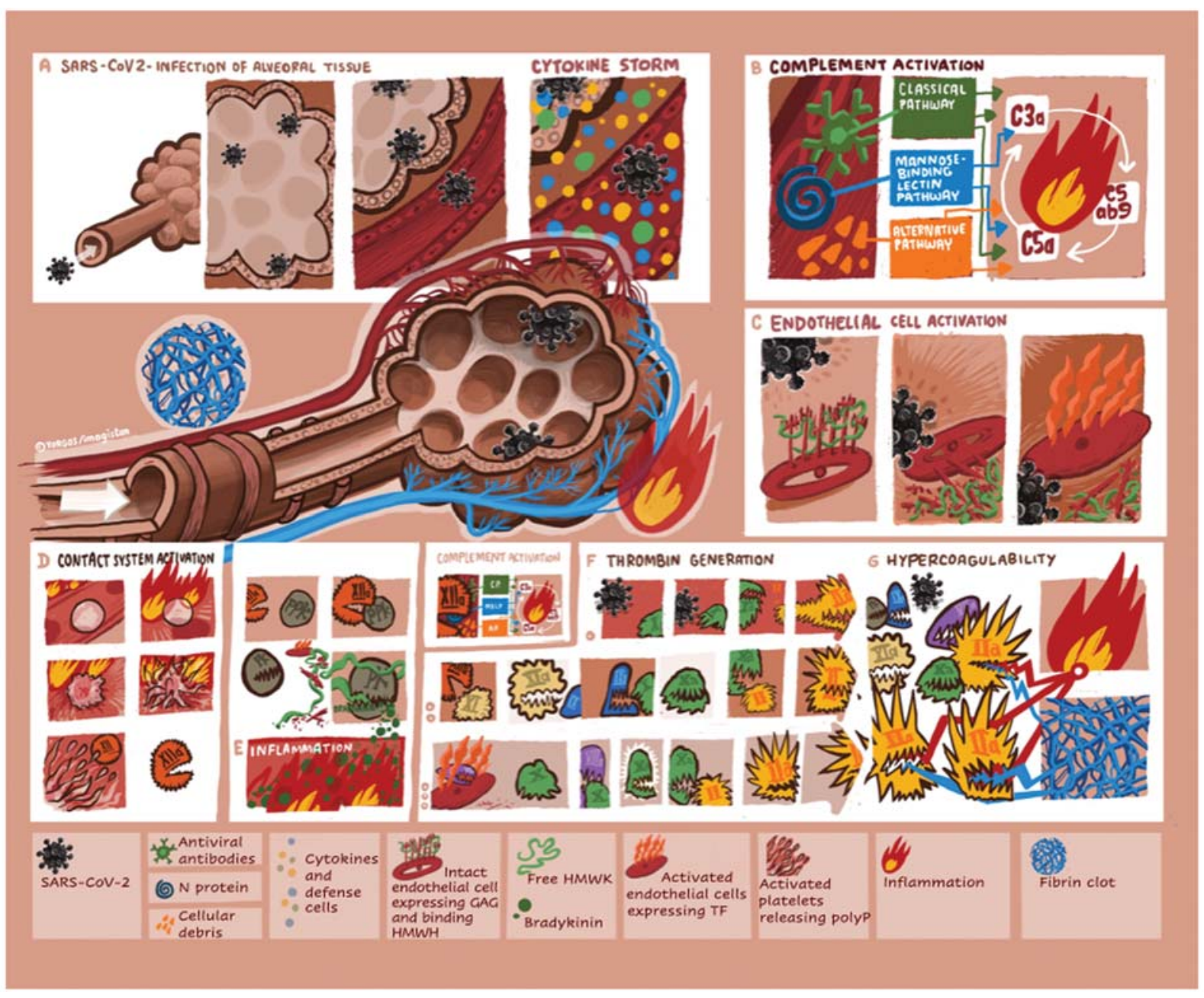

Fig. 1 The principal mechanisms triggered by SARS-CoV-2 infection leading to enhanced thrombin generation and pulmonary intravascular coagulation. GAG, glycosaminoglycans; HMWK, high-molecular-weight kininogen; IL, interleukin; INF, interferon; NET, neutrophil extracellular trap; PK, plasma kallikrein; PPK, plasma prekallikrein; TNF $\alpha$, tissue necrosis factor $\alpha$. 
patients document thrombotic microangiopathy involving the lungs as an important mechanism that contributes to death. The pulmonary pathological changes of fatal COVID19 are diffuse alveolar damage (DAD), accompanied by thrombosed small vessels with capillary hyaline thrombi, intravascular mixed thrombi, and significant associated hemorrhages. Endothelial cells, megakaryocytes, and platelet activation with microcirculation abnormalities implicating blood hypercoagulability are orchestrated in the process of disease aggravation and death. Patients present a high density of alveolar megakaryocytes and platelet-rich clot formation, in addition to fibrin deposition. Patients who had a more protracted hospital course had extensive and early organized fibrin network, with degenerated neutrophils within the alveoli possibly representing NETs. ${ }^{40-44}$ Lung microcirculation is characterized by the presence of viral elements within endothelial cells, accumulation of inflammatory cells, and endothelial inflammatory cell apoptosis. The ensemble of these histological and morphological abnormalities documents the existence of endotheliitis in several organs as a direct consequence of SARS-CoV-2 involvement and the host inflammatory response. ${ }^{45}$ The diffuse bilateral pulmonary inflammation observed in COVID19 is associated with a novel pulmonary-specific vasculopathy which has been termed "pulmonary intravascular coagulopathy" (PIC) as distinct to DIC. ${ }^{46}$

The clinical and computed tomography (CT) characteristics of PE in patients with COVID-19 were substantially different to those from patients with PE without COVID-19. ${ }^{47}$ Autopsy evidence in COVID-19 patients showed rough dilatation of the pulmonary artery branches and extensive thrombosis of the small arterioles, in keeping with a PElike pattern. ${ }^{48}$ Filling defects of pulmonary vessels that are detected by CT-scans are in many instances more reminiscent of pulmonary thrombi rather than emboli, because they are not fully occlusive. ${ }^{49}$ These initial observations were confirmed by autopsy findings in 21 hospitalized COVID19 patients which showed severe capillary congestion (capillarostasis). Microthrombi were detected in alveolar capillaries and were linked to PIC. Moreover, $20 \%$ of the patients had PE and $18 \%$ had evidence of DIC in the kidneys, despite anticoagulation. ${ }^{50}$ These data provide autopsy-based evidence of the link between endotheliitis, coagulopathy, and complement-mediated multifocal microvascular injury in different organs, as well as skin injuries in concert with pulmonary capillarostasis. In addition, some evidence highlights abnormalities in lung perfusion with microvascular shunting surrounding areas of inflammation with worsening of gas exchanges. ${ }^{51}$

Kidney biopsy analysis in patients with COVID-19 and associated kidney injury showed acute tubular necrosis as the dominant pathology followed by findings of thrombotic microangiopathy. However, immunohistochemical staining of kidney biopsy samples for SARS-CoV-2 was negative and an ultrastructural examination by electron microscopy showed no evidence of viral particles in the biopsy samples. ${ }^{52}$

The ensemble of the data available so far indicates that in patients with severe COVID-19 the SARS-CoV-2 triggers a vicious cycle of inflammatory reaction, excessive immunological response, endothelial cell activation, and hypercoagulability leading to organ dysfunction, whereas the evolution toward clinical deterioration may not be directly related with the presence of the virus.

\section{Autopsy Documented Venous Thromboembolism in COVID-19}

A large series of 80 autopsies performed in Hamburg showed that the most frequent cause of death in patients with COVID-19 is pneumonia, followed by pulmonary artery embolisms combined with pneumonia. ${ }^{53}$ Deceased had CVDs (85\%), lung diseases (55\%), central nervous system diseases (35\%), kidney diseases (34\%), diabetes mellitus $(21 \%)$, obesity $(21 \%)$, and solid or hematological cancer (16\%). The incidence of autopsy documented VTE was $42.5 \%$. The incidence of PE was $21 \%$. In $10 \%$ of patients, fatal fulminant pulmonary artery embolism was identified, whereas peripheral PE was found in other $11 \%$ of deceased patients. All cases with PE had also DVT. In additional 19\% of cases, DVT was documented without PE. The male deceased also showed thrombi in the prostatic venous plexus in 15 cases and in the veins of the esophagus in one case. Importantly, 10 out of 26 patients (38\%) who died at home had VTE showing that the risk of VTE is not determined only by hospitalization but mainly by SARS-CoV-2 infection and COVID-19 severity. A comprehensive review of the histological lung lesions reported in the autoptic studies in patients with COVID-19 confirms the importance of VTE together with DAD, PIC, and endotheliitis in the disease-worsening process. $^{54}$

\section{VAS Statement on Hypercoagulability, Endothelial Cell Activation, and Research on the Future Targeted Therapies for COVID-19}

- SARS-CoV-2 infection leading to severe COVID-19 implicates immune response, endothelial cell dysfunction, platelets, and complement activation, which are related with worsening disease and death. These pathways lead to initiation and enhancement of thrombin generation via the contact system and the TF pathways.

- Microvascular thrombosis at the lungs and other organs and PE are major causes of morbidity and mortality in patients with severe or critical COVID-19.

- COVID-19 is a major risk factor of VTE which may occur in the outpatient setting, during hospitalization, and even after hospital discharge.

- Targets for new therapies in COVID-19 include:

- Endothelial cell activation induced by SARS-CoV-2.

- Inhibition of serine proteases expressed by SARS$\mathrm{CoV}-2$ and investigation of the potentially inhibitory effect of direct and indirect inhibitors of thrombin or FXa.

- Inhibition of the complement, the contact system, and the intrinsic pathway of blood coagulation.

- Focused research is required on the possible relationship between the pre-existing activation status of endothelial 
cells in patients with VD-CVR upon exposure to the SARSCoV-2 and the risk of severe or critical illness.

- There is a need for therapeutic strategies aiming the prevention and treatment of "endotheliitis" and PIC upon SARS-CoV-2 infection. Antithrombotic agents (antiplatelet and anticoagulant drugs) and agents targeting the endothelium (i.e., statins, sulodexide, dermatan sulfate, etc.) are potential treatments requiring further investigations.

- Full pathological examination is an important tool to better understand the pathophysiology of diseases, especially when the knowledge of an emerging disorder is limited and the impact on the health care system is significant. VAS calls for performing well-conducted autopsies of deceased COVID-19 patients.

\section{Patients with Vascular Disease or Cardiovascular Risk Factors at Risk of COVID- 19 Worsening}

\section{Profile of COVID-19 Patients at Risk of Disease Worsening}

Patients with VD-CVR and particularly elderly patients are at high risk for severe COVID-19. Cardiovascular presentation in the setting of COVID-19 may be atypical, underpinning the importance of a high level of clinical suspicion of potential COVID-19 cases. Analysis of more than 8,900 COVID-19 patients hospitalized in North America, Europe, and Asia found that $30.5 \%$ of them had hyperlipidemia, $26.3 \%$ had arterial hypertension, $14.3 \%$ had diabetes mellitus, $16.8 \%$ were former smokers, and only 5.5\% were current smokers. In terms of cardiopathy, $11.3 \%$ had coronary artery disease and $2.1 \%$ had congestive heart failure. ${ }^{55}$ Myocardial injury with an elevated troponin level occurred in up to $17 \%$ of patients hospitalized with COVID-19 and 22 to $31 \%$ of those were admitted to ICUs and up to $7 \%$ of the COVID-19-related deaths were attributable to myocarditis. ${ }^{56-60}$ The frequency of cardiac arrhythmia among hospitalized COVID-19 patients was approximately $3.4 \%$, being at the same levels as the arrhythmia prevalence in general population with similar age. $^{61}$
A meta-analysis of 1,527 patients with COVID-19 found that the prevalence of arterial hypertension or cardiac disease was $17.1 \%$ and $16.4 \%$ respectively, and that these patients were more likely to require critical care. ${ }^{62}$ Underlying CVD is associated with more severe COVID-19 and higher mortality. ${ }^{60,63}$ Data analysis of 44,672 patients with COVID19 found that a history of CVD was associated with a nearly fivefold increase of case fatality rates when compared with patients without CVD (10.5 vs. $2.3 \%){ }^{63}$

A more recent meta-analysis of 13 studies including 3,027 patients with SARS-CoV-2 infection confirmed that age $>65$ years, male gender, arterial hypertension, diabetes mellitus, CVD, and respiratory disease are significant risk factors for severe COVID-19, disease worsening, and death. ${ }^{64}$

Patients with diabetes mellitus and COVID-19 infection are at a higher risk of admission to the ICU and mortality. ${ }^{65}$ Hyperglycemia is associated with vascular endothelial cell dysfunction. ${ }^{66}$ Efficacious control of glycemia in diabetic patients is mandatory for decreasing the risk of severe COVID-19. Well-controlled blood glucose levels (glycemic variability within $3.9-10.0 \mathrm{mmol} / \mathrm{L}$ ) in people with type 2 diabetes mellitus was associated with a markedly lower mortality compared with individuals with poorer glycemic control (upper limit of glycemic variability exceeding $10.0 \mathrm{mmol} / \mathrm{L}$; adjusted hazard ratio [HR]: 0.14) during hospitalization. ${ }^{67}$ Male gender, age $>65$ years, coronary artery disease, congestive heart failure, cardiac arrhythmia, and chronic obstructive pulmonary disease are associated with a higher risk of in-hospital death. The prevalence of cardiovascular risk factors for disease worsening and the relative risk of critical disease are summarized in -Table 1.

\section{Peripheral Arterial Disease and Risk of COVID-19 Worsening}

Peripheral arterial disease has a prevalence of up to $25 \%$ in men and women older than 70 years and is largely underdiagnosed. ${ }^{68,69}$ Limited data are available on the risk for severe COVID-19 in patients with PAD. The risk for vascular complications in such COVID-19 patients might be underestimated. Reciprocally, some limited data show that COVID19 is a risk factor for acute limb ischemia in patients with

Table 1 Summary of the range of the prevalence of cardiovascular disease, cardiovascular risk factors, and other comorbidities related to disease worsening in patients hospitalized with COVID-19 as reported in various studies ${ }^{55-64}$

\begin{tabular}{|l|l|l|l|}
\hline Comorbidities & Critical COVID-19 (\%) & Severe COVID-19 (\%) & $\begin{array}{l}\text { Odds ratio for disease } \\
\text { worsening (95\% CI) }\end{array}$ \\
\hline Diabetes & $14-60$ & $6-25$ & $2.13(2.68-5.1)$ \\
\hline Hypertension & $15-64$ & $7-39$ & $3.34(1.72-5.47)$ \\
\hline CVD & $9-40$ & $1-10$ & $5.19(3.25-8.29)$ \\
\hline Respiratory disease & $5-10$ & $1-8$ & $5.15(2.51-10.5)$ \\
\hline Malignancy & $1.5-10$ & $1-6$ & $1.6(0.81-3.18)$ \\
\hline Obesity & 31 & 8 & $5.4(2.77-10.67)$ \\
\hline Chronic renal disease & 19 & 7 & $2.92(1.04-6.09)$ \\
\hline
\end{tabular}

Abbreviations: $\mathrm{Cl}$, confidence interval; CVD, cardiovascular disease. 
PAD. ${ }^{70,71}$ Similarly there is lack of evidence on the risk for developing severe COVID-19 in patients with other forms of vascular disease (i.e., lymphatic or microcirculatory disease).

Risk of Arterial Thrombosis in Patients with COVID-19 Surprisingly, although the CVD and the cardiovascular risk factors are major predictors of disease worsening and death, the incidence of arterial thrombosis is much lower as compared with that of VTE. In a single-center study from Madrid on 1,419 hospitalized patients with COVID-19, only 14 patients (1\%) presented arterial thrombosis (acute coronary syndrome, acute ischemic stroke, transient ischemic attack, limb infrapopliteal thrombotic event) during their hospitalization period. The mortality rate in these patients was $28 \% .{ }^{72}$ In a French study enrolling 184 patients with COVID-19 admitted at the ICU, only seven patients had arterial thrombosis (3.8\%), of whom two had systemic arterial embolism. Interestingly, 68 patients (37\%) had VTE. ${ }^{73}$ Similarly, in a cohort of 388 hospitalized patients with COVID-19 in Milan, the incidence of arterial thrombosis (ischemic stroke and acute coronary syndrome) was also limited (3.6\%) compared with the cumulative rate of VTE (21\%: $27.6 \%$ in ICUs and 6.6\% in conventional wards). ${ }^{74}$

\section{Skin Manifestations and Chilblains in COVID-19 Patients}

Cutaneous manifestations in COVID-19 patients may present in two major groups regarding their pathogenetic mechanisms: (1) clinical features similar to viral exanthems induced by the immune response to viral nucleotides and (2) cutaneous eruptions secondary to systemic consequences caused by COVID-19, especially vasculitis and thrombotic vasculopathy. ${ }^{75}$ Dermatological manifestations such as skin rash, urticaria, vesicles, and purpura have been also reported. ${ }^{76-81}$ More recently, lesions resembling chilblains have been reported. ${ }^{82,83}$ Transient livedo reticularis has also been described. ${ }^{84}$

Chilblains in patients with COVID-19-described as COVID-19 toes-are being seen with an increasing frequency in children and young adults. Histopathology alterations in COVID-19 toes are characterized by variable degrees of lymphocytic vasculitis ranging from endothelial swelling and endotheliitis to fibrinoid necrosis and thrombosis. Purpura and superficial and deep perivascular lymphocytic inflammation with perieccrine accentuation or edema have been also described. The pathophysiology of chilblains is poorly understood. ${ }^{85}$ However, the presence of SARS-CoV2 in endothelial cells and epithelial cells of eccrine glands has been documented by histochemistry and electron microscopy. These data indicate a potential link between endothelial cell damage induced by the virus and the manifestation of chilblains ${ }^{86}$ Moreover, complement activation by the SARS$\mathrm{CoV}-2$ is probably implicated in this process but very limited data are available so far. ${ }^{8}$

Studies on the clinical usefulness of the measurement of complements (particularly C3 and C5) in patients with COVID-19 toes are strongly encouraged. Similarly, there are no data on therapeutic options in patients with COVID19 toes, including the evaluation of the efficacy of aspirin in this context.

\section{Specific Aims of Primary Health Care in the Management of Patients with Vascular Disease or Cardiovascular Risk Factors and COVID-19: Networking and Patient Involvement with e-Health} Lock-down policies in the case of epidemic waves should target in priority patients with VD-CVR. An emerging need is the elaboration of a COVID-19-oriented primary health care network using the tools of the e-Health (electronic health record templates, hospital information system dashboards, cloud-based medical image sharing, a mobile app, and smart vital-sign-monitoring wearable devices) for the management of these patients with nonsevere COVID-19 since some of them are at risk of disease worsening. ${ }^{87}$

Telemonitoring, televisit, and teleconsulting are encouraged to limit the effect of restricted access to physicians during, but not only, the epidemic or because of geographical limitations.

The organization of the eHealth network needs a connection of COVID-19 centers, with specialists in angiology/ vascular medicine, general practitioners, and hematological and biochemical laboratories for testing simple laboratory parameters mandatory for the disease evolution, image sharing facilities, utilization of "apps" offering a technology system for the follow-up of patients with VD-CVR and following the indications of the public health national systems. The network needs also to obtain an active, continue involvement of patients in disease control.

\section{VAS Recommendations for General Measures in Patients with Vascular Disease or Cardiovascular Risk Factors during the SARS-CoV-2 Epidemic}

- Patients with VD-CVR are at high risk of disease worsening and death upon SARS-CoV-2 infection. Patients with VD-CVR need to be identified at the community and registered at the regional COVID-19 centers and available angiology/vascular medicine centers.

- A regional procedure for prioritization of hospitalization of patients with VD-CVR with nonsevere COVID-19 who are at risk of disease worsening should be considered by health authorities.

- Educational programs must be elaborated for:

- Patients with VD-CVR aiming their training on early recognition of COVID-19 symptoms and the application of social distancing and self-protection measures.

- Physicians, particularly general practitioners and family doctors, aiming their training on early recognition of the risk of COVID-19 worsening and the implementation of the recommendations for the diagnosis and treatment of COVID-19.

- Physicians are advised to be aware of possible dermatological manifestations of COVID-19.

- Patients with VD-CVR should be under regular medical follow-up for: 
- The improvement of the adherence to the antihypertensive treatment (including ACE inhibitors or angiotensin receptor blockers), antiplatelet, and the lipid lowering treatment and the antihyperglycemic medications according to the recommendations of the relevant consensus statements and scientific societies.

- The monitoring of patients' physical activity (i.e., 6,000 steps per day) specially during the periods of lockdown measures and the registration of their clinical signs and symptoms of arterial disease.

- The psychological status of patients and family members particularly during epidemic waves.

- Patients with VD-CVR and nonsevere COVID-19 receiving medical care at home need close follow-ups and should be prioritized for hospital admission in case of COVID-19 worsening.

- e-Health is strongly recommended for patients with VDCVR during SARS-CoV-2 epidemic waves. Inside of the national health system, e-Health will enforce the network between COVID-19 centers, hospitals, centers of angiology/vascular medicine, general practitioners, other health workers, pharmacy, hematological/biochemical laboratories, and patients.

\section{VAS Recommendations for PAD Diagnosis during SARS-CoV-2 Epidemic}

- Physicians are advised to be aware of the most common symptoms and clinical signs of PAD (because it is an underdiagnosed vascular pathology) and to systematically perform appropriate physical examination upon medical visits at home or regular consultation, including measurement of ankle-brachial index particularly in elderly, smokers, and diabetic patients. They are also advised to include and collect data regarding PAD in the COVID-19 patients' database and to share them at the site https://www.vas-int.net/.

- From a general point of view, during COVID-19 epidemic:

- Nonurgent vascular exams have to be deferred to protect patients and aid in the management of COVID-19.

- For urgent vascular exams that have to be performed, practices have to be adjusted to best safeguard the technologist and the patient.

- Main clinical indications for urgent vascular exams include critical limb ischemia and stroke.

- Vascular ultrasound is the optimal exam for these conditions. All the other conditions/exams have to be considered elective and should be deferred.

- Portable, dedicated equipment, where available, should be used. Components not necessary should be removed, to make the process easier as well as for the equipment cleaning. Essential and competent staff should be involved in performing the exam, to obtain the most relevant result.

- Management of other acute/emergency conditions (aortic dissection, aneurism rupture, etc.) should follow the existing protocols.

\section{Antithrombotic and Vascular Modulating Treatments in Patients with COVID-19}

Blood-borne hypercoagulability in concert with endothelial cell activation and endotheliitis predisposes to severe COVID19 and patients with VD-CVR are prone to disease worsening. Inhibition of thrombin generation and platelet activation is an emerging therapeutic strategy, adjuvant to antiviral or immunological or other compassionate therapies.

The targets of the antithrombotic treatment in patients with VD-CVR during infection with SARS-CoV-19 and COVID-19 are (1) prevention and treatment of PIC and DIC, (2) prevention and treatment of VTE, (3) prevention of arterial thrombosis recurrence, and (4) prevention of disease worsening.

The potent inhibition of thrombin generation induced by unfractionated heparin (UFH), low-molecular-weight heparins (LMWHs), and direct oral anticoagulants (DOACs) places them into the first line for management of patients with VDCVR and COVID-19.

The pharmacological and pharmacodynamic properties of antithrombotic agents as well as the drug-drug interactions are of important relevance in these patients. Cytokine storm and inflammation, hypercoagulability and the eventual evolution to consumption coagulopathy, the rapid deterioration of the renal or hepatic function in patients with worsening disease, as well as the interactions with some of the experimental drugs might compromise the beneficial effect of some antithrombotic agents and may lead either to bleeding risk increase or treatment resistance. For these reasons, in the following section, we present the most important pharmacological and pharmacodynamic properties of the antithrombotic agents that might be proposed.

\section{Heparins}

Heparins are multitargeted antithrombotic agents. LMWHs are the most widely used antithrombotic agents for the prevention and treatment of VTE in hospitalized patients. UFH is more frequently used in patients with renal insufficiency. UFH and LMWH exert their antithrombotic effect primarily by the binding of the pentasaccharide domain (present in $~ 30 \%$ of the polysaccharide chains) on $\mathrm{AT}^{88} \mathrm{UFH}$ and LMWH stimulate the release of the TF pathway inhibitor from endothelial cells, exert a potent anti-inflammatory action, have immune modulating actions, inhibit complements and prevent the NET formation. Heparins may also competitively bind to coronavirus and inhibit its multicellular invasion. ${ }^{89-92}$

The high degree of sulfation of GAG chains makes heparin one of the most strongly anionic biological macromolecules. Heparin will therefore interact with any basic molecule it encounters. The intensity of this interaction depends on the molecular size and results in the inhibition of the antithrombotic activity of heparin. Longer GAG chains in UFH are more sulfated and show a higher nonspecific binding to basic molecules (i.e., platelet factor 4, fibronectin, vitronectin, annexin, or plasma inflammatory proteins) as compared with the shorter GAG chains of the LWMHs. ${ }^{93}$ Nonspecific binding of UFH with inflammatory proteins compromises 
the antithrombotic activity of UFH as documented by the high rates of resistance to UFH treatment in COVID-19. ${ }^{94}$ The smaller molecular size of polysaccharide chains in LMWHs, compared with that of UFH, involves a more predictable pharmacological action and better bioavailability after subcutaneous injection. ${ }^{95}$

The LMWHs vary in their physicochemical properties, the anti-Xa/anti-IIa ratio, and their inhibitory effect on thrombin generation. ${ }^{96,97}$ Therefore, the dosages for each one should be administered according to manufacturers' instructions.

Both UFH and LMWHs alter the clot firmness, an effect which is related to the physicochemical properties of GAG chains. ${ }^{98}$ This property of heparins might have some importance in the management of the hypercoagulable state and the risk of thrombosis in patients with COVID-19, since the inflammatory reaction in COVID-19 patients is associated with a high clot firmness. ${ }^{99}$

It is well documented that in clinical practice, the correlation between activated partial thromboplastin time (aPTT) prolongation and the UFH dose is rather poor. In patients with COVID-19, who need efficient anticoagulation, the monitoring of the treatment with UFH should be done with the measurement of the anti-Xa activity in plasma because the aPTT is influenced by the high levels of FVIII and fibrinogen. ${ }^{100,101}$ The potential presence of lupus anticoagulant or the deficiency of FXII in some patients with COVID-19 will lead to misleading results and erroneous dose modifications.

UFH is cleared from macrophages and endothelial cells and is preferred in patients with renal insufficiency. The LWMHs are cleared principally by the kidneys and their use should be cautious in patients with renal insufficiency. Hence, LMWHs with intermediate molecular weight, such as tinzaparin and dalteparin, showed limited accumulation of their anti-Xa activity in patients with severe renal impairment. ${ }^{102-104}$

The usual doses of available LMWH for the prevention and treatment of VTE as well as the adaptation of the doses according to the renal function are summarized in $\mathbf{- T a b l e ~} \mathbf{2}$.

\section{Direct oral Anticoagulants}

DOACs are classified with specific direct FXa inhibitors (apixaban, betrixaban, edoxaban, and rivaroxaban) and one specific direct thrombin inhibitor (dabigatran). All DOACs except betrixaban are indicated for the treatment and secondary prevention of VTE, and the prevention of ischemic stroke in patients with atrial fibrillation. Rivaroxaban and betrixaban have been studied in the prevention of VTE in hospitalized acutely ill medical patients as well as in extended prevention of VTE in outpatients after their hospital discharge. ${ }^{105-107}$

DOACs are principally excreted by kidneys and are contraindicated in patients with creatinine clearance lower than $15 \mathrm{~mL} / \mathrm{min}$, whereas dose adjustment is required for patients with renal clearance between 15 and $50 \mathrm{~mL} / \mathrm{min}$ (-Table 2).

DOACs are substrates for ABCB1 and P-glycoprotein (P-gp) transporters. Rivaroxaban and apixaban are metabolized by
CYP3A4, CYP2J2, and also CYP-independent mechanisms prior to elimination. ${ }^{108}$ Doses of DOACs for the prevention and treatment of VTE and dose adaptation according to renal function are summarized in -Table 2. Major P-gp inhibitors can increase the absorption of DOACs inducing a significant accumulation of the drug, increasing bleeding risk. Conversely, major P-gp inducers can reduce the DOAC absorption, reducing potentially their antithrombotic efficacy.

\section{Antiplatelet Treatment}

Antiplatelet treatment, including aspirin, clopidogrel, prasugrel and ticagrelor, is of major importance for secondary prevention of arterial thrombosis. Aspirin is the drug of choice for the prevention of arterial thrombosis in highrisk patients with cardiovascular risk factors.

Some in vitro studies showed that aspirin beyond the well-known antiplatelet and anti-inflammatory activities inhibits RNA virus replication also. ${ }^{109}$ Older studies have shown that prehospital use of antiplatelet agents and particularly aspirin has a potential beneficial effect on the risk of ARDS in acutely ill patients. ${ }^{110} \mathrm{~A}$ recent metaanalysis of seven studies, including 30,291 hospitalized patients, showed that those receiving prehospital treatment with antiplatelet agents (aspirin or clopidogrel) had a significantly lower risk of ARDS as compared to those with no prehospital antiplatelet therapy (odds ratio: 0.68, 95\% confidence interval [CI ]: 0.56-0.83; $p<0.001$ ). However, treatment with antiplatelet agents did not affect the mortality in ARDS patients. ${ }^{110,111}$ Based on this rationale, 11 studies registered in ClinicalTrials.gov (https://clinicaltrials. gov/ct2/results?cond=Covid $19 \&$ term $=$ aspirin \&cntry $=\&$ state=\&city=\&dist=) investigate the effect of early initiation of aspirin treatment if it mitigates the prothrombotic state and reduces hospitalization rates in patients with nonsevere COVID-19. Moreover, a small proof-of-concept study tested the effect of antiplatelet treatment with aspirin, clopidogrel, and tirofiban on the ventilation/perfusion ratio in COVID-19 patients with severe respiratory failure and showed some encouraging results. ${ }^{112}$

\section{Angiotensin-Converting Enzyme Inhibitors and Angiotensin Receptor Blockers and Risk of COVID-19 Worsening}

Angiotensin-converting enzyme inhibitors (ACEIs) and angiotensin II type- 1 receptor blockers (ARBs) are widely used drugs for the treatment of arterial hypertension, heart failure, and chronic kidney disease. These antihypertensive agents enhance the expression of ACE2 which has a central place in cell infection by the SARS-CoV-2. From a mechanistic point of view, there is a hypothesis that treatment with ACEIs or ARBs might increase the risk of SARS-CoV-2 infection or COVID-19 worsening. However, the studies published so far did not confirm this hypothesis. ${ }^{113,114}$ The most recent study form China on 2,263 patients with arterial hypertension, receiving $\geq 1$ antihypertensive agents, and who had a positive outpatient SARS-CoV-2 test showed that ACEI or ARB use was not associated with the risk of hospitalization or mortality. ${ }^{115}$ A smaller study from Italy on a cohort of 133 


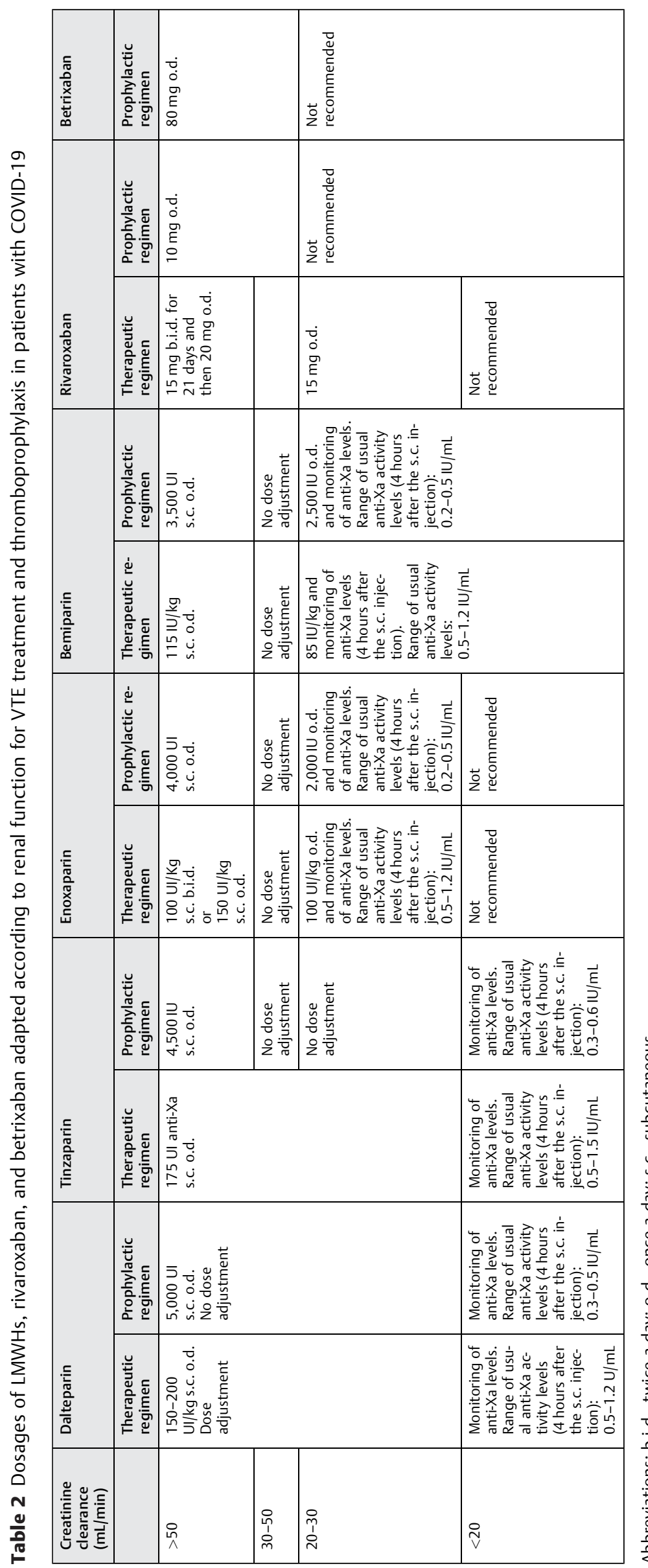


consecutive hypertensive subjects presenting to the emergency department with COVID-19 infection also showed that treatment with ACEIs did not negatively affect the clinical course of COVID-19. ${ }^{116}$

\section{Statins in COVID-19}

Dyslipidemia is recognized as a risk factor associated with microvascular dysfunction in arterial hypertension, diabetes mellitus, and cardiovascular disorders. ${ }^{117}$ The latter two are major risk factors of severe COVID-19 and death. Cholesterol plays an essential role in the activation/dysregulation of the immune response and in the onset and pathogenesis of ARDS. ${ }^{118,119}$ Cholesterol via the transport protein apolipoprotein $\mathrm{E}$ (apoE) enhances the endocytic entry of SARS-CoV2 to target cells. ${ }^{120}$ It could be involved in endothelial injury in COVID-19 patients. $^{121}$

Statin treatment might improve endothelial and vascular functions in these patients. Lastly, it has been suggested that statins could have a role in SARS-CoV-2 infection by blocking the virus entry to cells. ${ }^{122}$ A combination of statin/ARB treatments was used in an unconventional and poorly documented experience to target the host response and prevent endothelial barrier damage in Ebola patients during the outbreak in West Africa. A similar approach might be considered for patients with severe COVID-19 infection since both statins and ARBs upregulate ACE2 activity and counter endothelial dysfunction. ${ }^{123}$ The pleiotropic effects of statins have been studied in vitro but the clinical relevance of these finding has not been evaluated yet. At least nine clinical trials have been registered in ClinicalTrials.gov to evaluate if treatment with statin has any beneficial effect against disease worsening in patients with COVID-19 (https://clinicaltrials.gov/ct2/results?con$\mathrm{d}=$ Covid19\&term $=$ statin $\&$ cntry $=\&$ state $=\&$ city $=\&$ dist $=\&-$ Search=Search).

\section{Drug Interactions}

Patients with VD-CVR are usually under multidrug therapies (including antilipidemic agents, antihypertensive and/or antidiabetic agents, anticoagulant and/or antiplatelet agents). Therefore, drug interactions with antiviral or convalescence treatments should be systematically controlled. Among these treatments, dexamethasone, according to the preliminary report of an open label, controlled trial, significantly reduced the mortality rate in patients hospitalized with COVID-19 who were receiving either invasive mechanical ventilation or oxygen alone. ${ }^{124}$

No interactions have been reported between $\mathrm{LMWH}$, fondaparinux, UFH, or aspirin with the antiviral experimental drugs, or convalescence therapies, or dexamethasone in patients with COVID-19.

The P-gp and CYP450 systems in the liver (especially CYP3A4) are metabolic pathways of the DOACs. The same metabolic pathways are used by several antiviral drugs (especially lopinavir and ritonavir) which may alter DOACs' pharmacokinetics of as well as those of clopidogrel and ticagrelor. Lopinavir and ritonavir may potentiate CYP3A4 or P-gp inhibition leading to reduction of clopidogrel and increase of ticagrelor effects. Prasugrel is less influenced by this drug combination. ${ }^{125,126}$ Apixaban and rivaroxaban are also influenced by CYP3A4 and P-gp inhibition, while dabigatran and edoxaban are influenced only by P-gp inhibition.

The data available so far show that in hospitalized patients with COVID-19 who are on long-term antithrombotic treatment with DOACs, administration of antiviral drugs induces up to six times increase of peak and trough levels. ${ }^{127}$ Dosage of peak and/or trough DOAC concentrations in plasma might have some clinical relevance in the evaluation of the pharmacokinetics modification in patients treated with drugs with such interactions.

The anticoagulation induced by vitamin $\mathrm{K}$ antagonists (VKAs) is much more instable in COVID-19 patients due to the inflammatory state and the interactions with numerous drugs used including paracetamol.

Both DOAC and VKA present potentially clinically significant interactions with dexamethasone. Consequently, hospitalized patients with COVID-19 on DOACs or VKA should be switched to treatment with a therapeutic dose of LMWH.

The degrees of interactions between antithrombotic agents or lipid-lowering agents with the most common treatments in SARS-CoV-2 infection are depicted in -Fig. 2. An updated list of interactions between conventional drugs, including antithrombotic agents (antiplatelets and anticoagulant agents) antidiabetic, antihypertensive, and antilipidemic drugs and the ones used for the treatment of COVID-19 is available at http://www.covid19-druginteractions.org/ (created by Liverpool Drug Interaction Group).

\section{VAS Recommendations for the Use of antithrombotic Agents in Patients with Vascular Disease or Cardiovascular Risk Factors and COVID-19}

- LMWHs are the first-line antithrombotic treatment in patients hospitalized with COVID-19 because they offer predictive and stable antithrombotic effect following subcutaneous injection and show less than UFH nonspecific binding with plasma proteins, particularly during the cytokine storm. These are significant advantages of LMWHs particularly in critically ill patients who may present resistance to treatment with UFH.

- Resistance to UFH is a concern for the patients with COVID-19. The aPTT is not the optimum test for monitoring and dose adjustment of UFH treatment. The measurement of the anti-Xa activity should be preferred against aPTT for the biological monitoring and dose adjustment of the UFH treatment.

- Dalteparin or tinzaparin can be used as alternative treatments for patients with severe renal insufficiency and resistance to UFH. Monitoring of the anti-Xa activity in plasma at peak and trough levels should be regular and doses should be adapted accordingly.

- The target levels of anti-Xa activity in patients receiving a prophylactic dose of LMWHs, 4 hours after the subcutaneous injection, range from 0.2 to 0.5 anti-Xa IU $/ \mathrm{mL}$. 


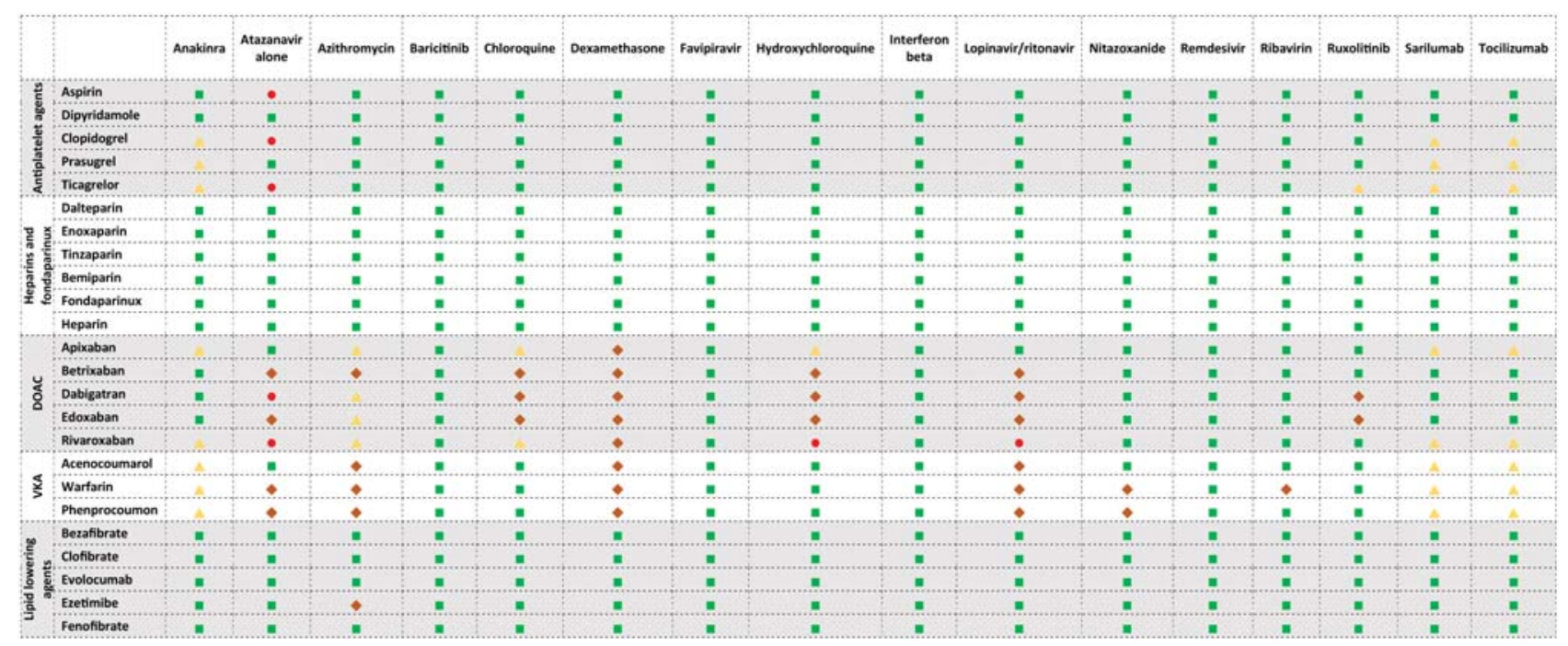

Fig. 2 Interactions of antithrombotic and lipid lowering agents with antiviral and convalescence treatment in patients with COVID-19. Drug combinations may have been assessed either by study or within the product label, or an interaction may have been predicted based on the metabolic profiles of the drugs. (data available in : https://www.covid19-druginteractions.org). Interpretation of colors: : These drugs should not be co-administered; $\$$ : Potential clinically significant interaction that is likely to require additional monitoring, alteration of drug dosage or timing of administration. : Potential interaction likely to be of weak intensity. Additonal action/monitoring or dosage adjustment is unlikely to be required. ${ }^{\text {: N }}$ No clinically significant interaction expected. VKA, Vitamin K antagonists; DOAC, direct orally active anticoagulants.

- The target levels of anti-Xa activity in patients receiving a therapeutic dose of LMWHs, 4 hours after the subcutaneous injection, range from 0.5 to 1.5 anti-Xa IU/mL.

- In hospitalized patients with COVID-19, DOACs and VKA should be replaced by LMWH due to potential interactions with antiviral or convalescence treatments.

- In the case that DOACs treatment cannot be replaced by LMWH, the interactions with the other drugs should be carefully controlled using at the Web site: http://www. covid19-druginteractions.org/. If these interactions exist, monitoring of peak and trough levels of DOAC concentration in plasma is encouraged.

- Antiplatelet agents are the cornerstone treatment for primary and secondary prevention of arterial thrombosis. Physicians who take care of patients with vascular disease and COVID-19 should control adherence and compliance of the antiplatelet treatment according to the recommendations of the relevant consensus statements and scientific societies.

- Physicians should be aware for the increase of bleeding risk when antiplatelet treatment is coadministrated with anticoagulant agents (i.e., LMWH or UFH). In patients receiving antiplatelet treatment and thromboprophylaxis with $\mathrm{LMWH}$, the bleeding risk must be carefully evaluated and the patients need to be under close medical follow-up.

- Management of the antithrombotic treatment before interventional procedures, as well in the case of bleeding, should be done according to the recommendations of the relevant consensus statements.

- Patients should continue to be treated with the recommended antihypertensive therapy and lipid-lowering agents during their disease trajectory.

\section{Blood-Borne Hypercoagulability and Risk of Disease Worsening and Death in Patients with COVID-19}

Hypercoagulable states together with lymphopenia, mild thrombocytopenia, and increased biomarkers of inflammation are common alterations in patients with COVID-19 hospitalized either at the conventional medical ward or at the ICU. 7,128 Hypercoagulability is based on the significant increase of D-dimer levels in the plasma as well as on the evidence of DIC; notably prolonged prothrombin time (PT) and/or aPTT, thrombocytopenia, and acquired AT deficiency.

\section{D-dimer in COVID-19}

Among the hematological biomarkers, D-dimers have attracted the attention of researchers and clinicians involved in the management of patients with COVID-19. Two systematic reviews highlight that D-dimer values are higher in nonsurvivors as well as in patients with severe COVID-19 than in those with mild disease. ${ }^{129,130}$ The most relevant studies showing the association between $\mathrm{D}$-dimer levels and disease severity or death are summarized in -Table 3.

Measurement of D-dimer at hospital admission has been proposed for the evaluation of the risk for death. Statistical significance of separation between patients with D-dimer $\geq 2.0 \mu \mathrm{g} / \mathrm{mL}$ and those with D-dimer $<2.0 \mu \mathrm{g} / \mathrm{mL}$ was achieved at 7 days after admission. Frequent monitoring of D-dimer during hospitalization might provide more information to predict death. ${ }^{131}$ However, this strategy has to be validated since the derivation study suffers from several methodological limitations (i.e., retrospective design, absence of validation cohort). ${ }^{132-135}$ 
Table 3 Association between D-dimer levels and disease severity or death in hospitalized patients with COVID-19

\begin{tabular}{|c|c|c|c|c|c|}
\hline $\begin{array}{l}\text { Study } \\
\text { references }\end{array}$ & $\begin{array}{l}\text { Sample } \\
\text { size }(n)\end{array}$ & $\begin{array}{l}\text { Conventional } \\
\text { ward median } \\
\text { D-dimer level } \\
\text { (range) }\end{array}$ & $\begin{array}{l}\text { ICU patient median } \\
\text { D-dimer level (range) }\end{array}$ & $\begin{array}{l}\text { Survivor median } \\
\text { D-dimer level (range) }\end{array}$ & $\begin{array}{l}\text { Nonsurvivor median } \\
\text { D-dimer level (range) }\end{array}$ \\
\hline Huang et al ${ }^{10}$ & 41 & $\begin{array}{l}500 \mathrm{ng} / \mathrm{mL} \\
(300-800 \mathrm{ng} / \mathrm{mL})\end{array}$ & $\begin{array}{l}2,400 \mathrm{ng} / \mathrm{mL} \\
(600-14,400 \mathrm{ng} / \mathrm{mL})\end{array}$ & NR & NR \\
\hline Fogarty et al ${ }^{46}$ & 83 & NR & $\begin{array}{l}1,210 \mathrm{ng} / \mathrm{mL}^{\mathrm{a}} \\
(603.5-3,623 \mathrm{ng} / \mathrm{mL})\end{array}$ & $\begin{array}{l}803 \mathrm{ng} / \mathrm{mL} \\
(529-1,549 \mathrm{ng} / \mathrm{mL})\end{array}$ & NR \\
\hline \multirow[t]{3}{*}{ Zhou et al ${ }^{134}$} & \multirow[t]{3}{*}{191} & \multirow[t]{3}{*}{ NR } & \multirow[t]{3}{*}{ NR } & $\begin{array}{l}\text { D-dimer } \leq 500 \mathrm{ng} / \mathrm{mL} \\
43 \%\end{array}$ & $7 \%$ \\
\hline & & & & $\begin{array}{l}\text { D-dimer: } \\
500-1,000 \mathrm{ng} / \mathrm{mL} 33 \%\end{array}$ & $11 \%$ \\
\hline & & & & $\begin{array}{l}\text { D-dimer }>1,000 \mathrm{ng} / \mathrm{mL} \\
24 \%\end{array}$ & $81 \%^{b}$ \\
\hline Wu et $\mathrm{al}^{143}$ & 201 & $\begin{array}{l}520 \mathrm{ng} / \mathrm{mL} \\
(330-930 \mathrm{ng} / \mathrm{mL})\end{array}$ & $\begin{array}{l}1,160 \mathrm{ng} / \mathrm{mL} \\
(460-5,370 \mathrm{ng} / \mathrm{mL})\end{array}$ & NR & $\begin{array}{l}3950 \mathrm{ng} / \mathrm{mL} \\
(1150-10,960 \mathrm{ng} / \mathrm{mL})^{c}\end{array}$ \\
\hline Tang et al ${ }^{149}$ & 183 & NR & NR & $\begin{array}{l}\text { Median D-dimer level: } \\
610 \mathrm{ng} / \mathrm{mL} \\
\text { Range: } \\
350-1,290 \mathrm{ng} / \mathrm{mL}\end{array}$ & $\begin{array}{l}\text { Median D-dimer level: } \\
2,120 \mathrm{ng} / \mathrm{mL} \\
\text { Range: } \\
770-5,270 \mathrm{ng} / \mathrm{mL}\end{array}$ \\
\hline Guan et al ${ }^{191}$ & 1,099 & $\begin{array}{l}44 \% \text { of patients } \\
\text { had } D \text {-dimer } \\
\geq 500 \mu \mathrm{g} / \mathrm{L}\end{array}$ & $\begin{array}{l}60 \% \text { of patients had } \\
\text { D-dimer } \geq 500 \mu \mathrm{g} / \mathrm{L}\end{array}$ & NR & $\begin{array}{l}64 \% \text { of patients had } \\
\geq 500 \mu \mathrm{g} / \mathrm{L} \\
(p=0.001 \text { vs. nonsevere } \\
\text { patients })\end{array}$ \\
\hline Wang et al ${ }^{135}$ & 138 & $\begin{array}{l}166 \mathrm{ng} / \mathrm{mL} \\
(101-285 \mathrm{ng} / \mathrm{mL})\end{array}$ & $\begin{array}{l}414 \mathrm{ng} / \mathrm{mL} \\
(191-1,324 \mathrm{ng} / \mathrm{mL})\end{array}$ & $<500 \mathrm{ng} / \mathrm{mL}$ & $1,200 \mathrm{ng} / \mathrm{mL}$ \\
\hline
\end{tabular}

Abbreviation: NR: not reported.

${ }^{a} \mathrm{ICU}$ patients and nonsurvivors.

${ }^{\mathrm{b}} \mathrm{High} \mathrm{D}-\mathrm{dimer}$ level was associated with a higher odds ratio of death $(\mathrm{OR}=18.42,95 \% \mathrm{Cl}: 2.64-128.55 ; p=0.0033)$.

${ }^{c} H i g h$ D-dimer level was associated with ARDS development $(\mathrm{HR}=1.03,95 \% \mathrm{Cl}: 1.01-1.04, p<0.001)$ and poor survival $(\mathrm{HR}=1.02,95 \% \mathrm{Cl}: 1.01-$ $1.04, p=0.002$ ).

D-dimers are degradation products of cross-linked fibrin, indicating enhanced fibrin formation and activation of the fibrinolytic system. D-dimers and fibrinogen concentrations in plasma are closely correlated. Moreover, D-dimer concentration indirectly reflects in vivo thrombin generation, since thrombin is the enzyme responsible for fibrinogen cleavage and fibrin monomer formation. However, D-dimer is not a specific biomarker for thrombosis. Levels of D-dimer reflect the inflammatory process and an increase in several conditions such as cancer, pregnancy, trauma, CVD, diabetes mellitus, etc. Noteworthy, levels of D-dimer are frequently increased in patients with VD-CVR independently of SARSCoV-2 infection. ${ }^{136,137}$ Moreover, D-dimers do not directly reflect the activation state of endothelial cells. Taking into consideration these characteristics of D-dimer tests, it is expected that the positive or negative predictive value of the test, if it is used as a single predictor for the evaluation of the risk of disease worsening, is limited.

\section{Disseminated Intravascular Coagulation in COVID-19}

DIC is a life-threatening acquired syndrome which, according to the International Society on Thrombosis and Haemostasis (ISTH) definition, is characterized by the intravascular activation of coagulation and causes damage to the microvasculature, which if sufficiently severe can produce organ dysfunction. ${ }^{138}$ Early reports from China underline the presence of DIC in patients with COVID-19. On admission to the hospital, nonsurvivors with COVID-19 had significantly higher D-dimer levels and longer PT compared with survivors. By late hospitalization, fibrinogen and AT levels were significantly lower in nonsurvivors, suggesting that hypercoagulability and DIC were associated with an increased risk of death. ${ }^{139}$

It is important to underline that according to the ISTH Scientific Subcommittee, DIC may present as (1) compensated activation of coagulation with subtle hemostatic dysfunction and an increase in thrombotic risk without obvious clinical symptoms. This phase is characterized by an imbalance between activation and inhibition of the coagulation system. Deficiency of natural coagulation inhibitors (principally $\mathrm{AT}$ and $\mathrm{PC}$ ) and an increase of D-dimer are early coagulation abnormalities in patients with compensated DIC. (2) Overt DIC with significantly reduced hemostatic potential: this phase is characterized by the absence of normal regulatory mechanisms and collapse of hemostatic forces because of consumption of platelets, coagulation factors, and fibrinogen. This condition is also known as "consumption coagulopathy." Overt DIC is associated with both bleeding and thrombotic manifestations including both microvascular thrombosis and thrombosis of larger vessels. Compensated DIC may progress to overt DIC. ${ }^{140,141}$ 
The diagnosis of DIC is based on scoring systems including clinical and laboratory parameters. Today, there are five different diagnostic scoring systems for DIC established by (1) the ISTH, (2) the Japanese Ministry Health and Welfare, (3) the Japanese Association for Acute Medicine, (4) the British Committee for Standards in Haematology, and (5) the Italian Society of Thrombosis and Hemostasis. ${ }^{134}$ Among them, the DIC-ISTH score is the most widely used and has been applied in hospitalized COVID-19 patients. The DICISTH score exists in two forms: (1) for diagnosis and follow up of compensated DIC ( - Table $4 \mathbf{A}$ ) and (2) for diagnosis and follow up of overt DIC ( - Table $\mathbf{4 B}) .{ }^{142}$

Tang et al, using the overt DIC-ISTH score in 183 patients with COVID-19, found that overt DIC ( $\geq 5$ points) was diag-

Table 4 Score for DIC diagnosis proposed by ISTH in patients with COVID-19

\begin{tabular}{|c|c|c|}
\hline \multicolumn{3}{|c|}{ A. Compensated DIC-ISTH score for COVID-19 } \\
\hline Predictor & Threshold & Score \\
\hline $\begin{array}{l}\text { Confirmed } \\
\text { COVID-19 }\end{array}$ & Yes & 2 \\
\hline \multirow[t]{2}{*}{ Platelet count } & $>100 \times 10^{9} / \mathrm{L}$ & 0 \\
\hline & $<100 \times 10^{9} / \mathrm{L}$ & 1 \\
\hline \multirow{2}{*}{$\begin{array}{l}\text { PT } \\
\text { prolongation }\end{array}$} & $<3 \mathrm{~s}$ & 0 \\
\hline & $>3 \mathrm{~s}$ & 1 \\
\hline \multirow[t]{2}{*}{ D-dimers } & $\begin{array}{l}\text { Higher than that of the upper } \\
\text { normal limit adapted for the } \\
\text { age cut-off }\end{array}$ & 0 \\
\hline & $\begin{array}{l}\text { Less than that of the upper } \\
\text { normal limit adapted for the } \\
\text { age cut-off }\end{array}$ & 1 \\
\hline \multirow{2}{*}{$\begin{array}{l}\text { Antithrombin } \\
\text { activity }\end{array}$} & Normal & 0 \\
\hline & $\begin{array}{l}\text { Less than the lower normal } \\
\text { limit }\end{array}$ & 1 \\
\hline \multirow[t]{2}{*}{ Protein C } & Normal & 0 \\
\hline & $\begin{array}{l}\text { Less than the lower normal } \\
\text { limit }\end{array}$ & 1 \\
\hline \multicolumn{3}{|c|}{ B. Overt DIC-ISTH score } \\
\hline Predictor & Threshold & Score \\
\hline \multirow[t]{3}{*}{ D-dimers } & Strong increase $(\times 2-3)$ & 3 \\
\hline & Moderate increase $(\times 1.5)$ & 2 \\
\hline & No increase & 0 \\
\hline \multirow{3}{*}{$\begin{array}{l}\text { Platelet count } \\
(\times \mathrm{G} / \mathrm{L})\end{array}$} & $<50$ & 2 \\
\hline & $50-100$ & 1 \\
\hline & $>100$ & 0 \\
\hline \multirow{2}{*}{$\begin{array}{l}\text { Fibrinogen } \\
\text { level (mg/dL) }\end{array}$} & $<1.0$ & 1 \\
\hline & $\geq 1.0$ & 0 \\
\hline \multirow{3}{*}{$\begin{array}{l}\text { Prothrombin } \\
\text { time (s) }\end{array}$} & $>6$ & 2 \\
\hline & $3-6$ & 1 \\
\hline & $<3$ & 0 \\
\hline
\end{tabular}

Abbreviations: DIC, disseminated intravascular coagulation; ISTH, International Society on Thrombosis and Haemostasis. Note: DIC positive if the score is $\geq 5 .{ }^{142}$ nosed in $72 \%$ of the nonsurvivors in later stages of COVID-19. Only one survivor $(0.6 \%)$ matched the overt DIC criteria during hospital stay. The nonsurvivors had significantly higher levels of D-dimer and fibrinogen/fibrin-derived proteins and longer PT and aPTT compared with survivors on admission. By late hospitalization, fibrinogen and AT levels were also significantly lower in nonsurvivors. The median time from admission to DIC manifestation was 4 days (range: 1-12 days). Wu et al analyzed clinical and biological data from 201 patients with confirmed COVID-19; $41.8 \%$ of patients developed ARDS, $26.4 \%$ were admitted to the ICU, $33.3 \%$ received mechanical ventilation, and $22 \%$ died. ${ }^{143}$ Elevated C-reactive protein (CRP) and serum ferritin, prolonged PT, and high levels of D-dimer were significantly associated with a higher risk of ARDS. The median time from admission to developing ARDS was 2 days (interquartile range: $1-4$ days). Patients with ARDS who died had significantly increased levels of D-dimer compared with patients with ARDS who survived (difference: $2.10 \mu \mathrm{g} / \mathrm{mL} ; 95 \% \mathrm{CI}$ : $0.89-5.27 \mu \mathrm{g} / \mathrm{mL} ; p=0.001$ ). The difference in median levels of D-dimer between the death and survival groups was larger than that between the ARDS and non-ARDS groups, suggesting that DIC was on the pathway to death in some patients. A study from Ireland enrolled 83 hospitalized patients with COVID-19 who routinely received thromboprophylaxis with enoxaparin (weight-adapted doses). ${ }^{144}$ Upon admission, PT and aPTT were within the normal range, platelet count was normal in $83 \%$ of patients, and fibrinogen was increased. Ddimers were higher than the upper normal limit in $67 \%$ of patients. The levels of D-dimer progressively increased during hospitalization, particularly in patients with disease worsening. Increases in D-dimer, fibrinogen, and CRP were significantly associated with poor prognosis. In contrast, PT and aPTT did not show any significant modification during hospitalization as compared with baseline values. None of patients either upon admission or during hospitalization in the conventional ward or in the ICU had an overt DIC (overt DIC-ISTH score $\geq 5$ ). These results, which are substantially different to those reported in patients from China, are attributed to the beneficial effect of thromboprophylaxis with LMWH on the evolution of coagulopathy.

However, all studies published so far show that thrombocytopenia is not a common finding in hospitalized patients with COVID-19. Moreover, PT and/or aPTT prolongation was observed particularly in ICU patients. Similarly, the frequency of hypofibrinogenemia is rather low in patients with COVID-19 hospitalized in the ICU. ${ }^{35}$ Accordingly, the frequency of clinically relevant or major bleeding is low in patients with COVID-19. Only $6.4 \%$ of COVID- 19 patients who died met overt DIC-ISTH criteria. ${ }^{145}$

The AT level is one of the predictors of the compensated DIC-ISTH score which is mandatory for poor clinical outcome in patients with sepsis-associated DIC. The scores for DIC diagnosis have been developed and validated mainly in patients with sepsis.

Compensated DIC is an independent risk factor for disease worsening in patients hospitalized with COVID-19. This is documented by a prospective observational study enrolling 
430 hospitalized patients with COVID-19. The compensated DIC-ISTH score was $\geq 5$ in $8.2 \%$ of patients hospitalized at the conventional ward and in $28.2 \%$ of patients in the ICU with disease worsening. However, the accuracy of the compensated DIC-ISTH score to identify patients at high risk for disease worsening was low. In hospitalized patients with COVID-19, disease worsening was also related to the presence of cardiovascular risk factors (i.e., arterial hypertension, diabetes mellitus, and obesity), chronic kidney disease, Ddimer increase, lymphopenia, anemia, and blood hypercoagulability. This study led to the derivation and validation of the COMPASS-COVID-19 risk assessment model (RAM) for early identification of patients with COVID-19 being at high risk of disease worsening. The COMPASS-COVID-19 score ( - Table 5), accessible online at www.medupdate.eu includes the following predictors for disease worsening: presence of obesity (BMI $\geq 30$ ), gender, hemoglobin, lymphocyte count, and compensated DIC-ISTH score $(\geq 5){ }^{146}$

So far, there is no available study proving any potential correlation between hypercoagulability, DIC-ISTH score, or Ddimer with the PIC occurrence. Moreover, beyond the autopsy studies, there is no validated surrogated marker for PIC diagnosis.

The need of serial assessments of hypercoagulability for prompt therapeutic intervention, early diagnosis of VTE, and optimization of antithrombotic treatment has already been stressed out. ${ }^{147,148}$

\section{Treatment of Hypercoagulability, PIC, and DIC in Patients with COVID-19}

Hypercoagulability is a common and early alteration in patients with COVID-19 related with the thrombosis risk, disease worsening, and death. Consequently, antithrombotic treatment is a cornerstone therapeutic strategy in patients with COVID-19. Heparins (LMWH or UFH) are the first-line treatment for inhibition of this thrombogenic state in hospitalized patients with COVID-19, which potentially could improve the global clinical outcome beyond the prevention of VTE. Therapeutic effect of heparin treatment has been evaluated in three studies published so far and is under evaluation in 35 trials registered in ClinicalTrials.gov.

Heparin Therapy and Mortality in Patients with COVID-19 Tang et al evaluated the 28-day mortality in heparin users and nonusers, among severe COVID-19 patients. In total 449 patients with severe COVID-19 were enrolled into the study. Among them, only 94 received LMWH (4,000-6,000 anti-Xa IU enoxaparin once daily) and five received UFH (10,000-15,000 IU/d), for 7 days or longer. The sepsis-induced coagulopathy (SIC) score was evaluated using the combination of PT, platelet count, and sequential organ failure assessment. D-dimers were also measured. Ninety-seven patients (21.6\%) met the SIC criteria (total score $\geq 4$ ) and they were classified as severe cases. The D-dimer, PT, and age were positively and platelet count was negatively correlated with the 28-day mortality. The mortality rate in the ensemble of the cohort was $29.8 \%$. No difference on the 28 -day mortality was found between heparin users and nonusers (30.3 vs. $29.7 \%, p=0.910$ ). Patient stratification according to the SIC score showed that heparin treatment was associated with a lower mortality in patients with SIC score $\geq 4$ ( 40.0 vs. $64.2 \%$, $p=0.029$ ), but not in those with SIC score $<4$ ( 29.0 vs. $22.6 \%$, $p=0.419$ ). Patient stratification according to the D-dimer levels showed a $20 \%$ reduction in mortality with heparin treatment when D-dimers were exceeding 3,000 ng/mL (sixfold of upper limit of normal; 32.8 vs. $52.4 \%, p=0.017) .{ }^{149}$

Table 5 The COMPASS-COVID-19 score for the evaluation of the risk for worsening disease in patients with COVID-19

\begin{tabular}{|c|c|c|}
\hline \multicolumn{3}{|l|}{ COMPASS-COVID-19 RAM } \\
\hline \multicolumn{2}{|l|}{ Predictors for risk of worsening disease } & Score \\
\hline \multicolumn{2}{|l|}{ Obesity (BMI > 30) } & 19 \\
\hline \multicolumn{2}{|l|}{ Male gender } & 10 \\
\hline \multicolumn{2}{|l|}{ Compensated DIC-ISTH score $\geq 5$} & \multirow{8}{*}{9} \\
\hline Confirmed COVID-19 & 2 & \\
\hline Thrombocytopenia (platelet count $<100,000 / \mu \mathrm{L}$ ): & 1 & \\
\hline Prothrombin time prolongation (> control $+3 \mathrm{sec}$ ): & 1 & \\
\hline $\begin{array}{l}\text { D-dimer increase }(>500 \text { for age }<60 \text { years; }>600 \mathrm{ng} / \mathrm{ml} \text { for age } 60-59 \text { years; } \\
>600 \mathrm{ng} / \mathrm{ml} \text { for age } 60-69 \text { years; }>700 \mathrm{ng} / \mathrm{ml} \text { for age } 70-79 \text { years; } \\
>800 \mathrm{ng} / \mathrm{ml} \text { for age } 80-89 \text { years; }>900 \mathrm{ng} / \mathrm{ml} \text { for age } 90-99)\end{array}$ & 1 & \\
\hline Antithrombin decrease (< lower normal limit established by the laboratory) & 1 & \\
\hline Protein C decrease ( $<$ lower normal limit established by the laboratory) & 1 & \\
\hline Total & $\geq 5$ & \\
\hline \multicolumn{2}{|l|}{ Lymphocytes $<10^{9} / \mathrm{L}$} & 8 \\
\hline \multicolumn{2}{|l|}{ Hemoglobin <11 g/dL } & 8 \\
\hline \multicolumn{2}{|l|}{ Total } & $\begin{array}{l}\geq 18: \text { high risk } \\
<18 \text { : low risk }\end{array}$ \\
\hline
\end{tabular}

Abbreviations: BMI, body mass index; DIC, disseminated intravascular coagulation; ISTH, International Society on Thrombosis and Haemostasis. 
A retrospective analysis from New York hospitals including 2,773 hospitalized patients with COVID-19 showed that antithrombotic treatment was systematically administered to $28 \%$ of them. However, the type of treatment, the dose, and the duration were not reported. In-hospital mortality for patients treated with anticoagulants was $22.5 \%$ with a median survival of 21 days, compared with $22.8 \%$ and a median survival of 14 days in patients who did not receive anticoagulant treatment.

In ICU patients $(n=395)$, the in-hospital mortality was $29.1 \%$ with a median survival of 21 days for those treated with anticoagulants as compared with $62.7 \%$ with a median survival of 9 days in patients who did not receive anticoagulant treatment. Overall, a longer duration of anticoagulant treatment was associated with a significantly reduced risk of mortality (adjusted HR of 0.86 per day, $95 \% \mathrm{CI}: 0.82-0.89$, $p<0.001$ ). The rate of major and clinically relevant hemorrhage in those receiving or not receiving anticoagulant treatment was 3 and $1.9 \%$, respectively. Bleeding events were more common among ICU patients (7.5\%) than among less severe nonintubated patients (1.35\%), underlining the need for careful evaluation of the bleeding risk and application of individualized anticoagulant treatment. Despite the design limitations, this study provides encouraging data for the global beneficial effect of anticoagulant treatment in hospitalized COVID-19 patients. $^{150}$

Ayerbe et al retrospectively analyzed data from 2,075 patients with COVID-19 admitted in 17 hospitals in Spain. The mortality rate in 1,734 patients who received heparin was $14 \%$, whereas in those who did not receive heparin $(n=285)$, it was $15.4 \%$. Heparin was associated with a significantly lower mortality when the model was adjusted for age and gender (odds ratio [OR]: $0.55 ; 95 \% \mathrm{CI}: 0.37-0.82$; $p=0.003){ }^{151}$

Many centers have increased the dose of anticoagulant prophylaxis to "intermediate-intensity" doses, such as $50 \mathrm{IU} /$ $\mathrm{kg}$ twice daily or $100 \mathrm{IU} / \mathrm{kg}$ once daily of enoxaparin, using a risk-adapted strategy with increased doses based on Ddimer levels, fibrinogen rate, ICU location, or other clinical factors associated with increased VTE risk. ${ }^{152,153}$ A Delphi method consensus document found that $31.6 \%$ of participant experts supported an intermediate-intensity dose and only $5.2 \%$ supported a therapeutic dose; the rest (63\%) supported the use of standard VTE prophylaxis dose for hospitalized patients with moderate to severe COVID-19 and lack of DIC. ${ }^{9}$

The ensemble of these recommendations for the diagnosis and treatment of DIC in patients with COVID-19 is summarized in - Table 6 .

These studies are derived from retrospective analysis of real-life practice during the epidemic and indicate that heparin administration in hospitalized patients with COVID-19 might have some beneficial effect on patients' mortality. However, they share several important limitations:

- The studied groups of patients were either heterogeneous or precisions on their characteristics were not provided.

- The antithrombotic regimens were not specified (i.e., type of heparin, dose, duration, dose modifications).
- The retrospective design and the absence of control group did not allow conclusions to be made on whether antithrombotic treatment has any effect on patients' mortality.

Nevertheless, it is important to note that $35 \%$ of physicians treating COVID-19 patients consider that usual prophylactic doses of LMWH are inadequate for effective management of the global thrombotic risk in hospitalized COVID-19 patients. This finding reflects the clinical perception that antithrombotic treatment with heparin is an essential part of the global therapeutic strategy for hospitalized patients with COVID-19 and requires optimization.

\section{Other Treatments for the Management of Hypercoagulability and PIC Prevention}

AT levels' evolution in COVID-19 patients is of particular interest since it is a major serine protease inhibitor that stoichiometrically inhibits thrombin, FXa, FVIIa, FIXa, and FXIa. Low AT levels may lead to failure of this procoagulant serine protease inhibition and compromise heparin efficacy since its antithrombotic activity is AT-dependent. Low levels of AT in the plasma of patients with sepsis-associated DIC are correlated with increased mortality. ${ }^{154}$ Substitution therapy with AT concentrates is a therapeutic option in patients with DIC and/or AT deficiency ( $<50 \%)$ as well as in certain clinical settings associated with inflammation. ${ }^{140,141}$ Ranucci et al in a small study enrolling 16 patients with COVID-19 and ARDS hospitalized in the ICU longitudinally assessed PT, aPTT, fibrinogen, D-dimer, thromboelastography, and AT activity. Upon ICU admission, all patients received LMWH thromboprophylaxis (4,000 anti-Xa IU twice daily). After the first round of standard coagulation and viscoelastic tests, the patients switched to 6,000 anti-Xa IU twice daily $(8,000$ anti-Xa IU twice daily if BMI was $>35$ ); AT concentrates were given to correct values $<70 \%$ and the clopidogrel loading dose of $300 \mathrm{mg}+75 \mathrm{mg} /$ day was associated with platelet count $>400 \mathrm{G} / \mathrm{L}$. AT deficiency was found in $25 \%$ of patients. ${ }^{155}$ Two of them received AT concentrate on day 2 of ICU hospitalization. Establishment of a more pronounced thromboprophylaxis (increased LMWH doses, AT correction, and clopidogrel use in the case of thrombocytosis) resulted in a significant downregulation of the hypercoagulable state. This study is a proof of concept and should be considered as pilot, since the prospective design and the longitudinal evaluation of hypercoagulability biomarkers allowed us to consider that the efficacy and safety of higher doses of LMWH and the resaturation of AT levels in COVID-19 patients are potentially effective therapeutic strategies. This should be investigated in prospective larger studies.

The need for sequential evaluation of the antithrombotic therapy efficacy in hospitalized patients with COVID-19 is emerging in an increasing number of studies showing that resistance to heparin is frequent particularly in ICU patients. ${ }^{94,153,156}$

Systemic thrombolysis with recombinant tissue plasminogen activator (tPA) has been also proposed in COVID-19 patients with ARDS aiming to the lysis of lung microcirculation thrombi. In two case series with a total of eight critically 
Table 6 International recommendations for diagnosis and treatment of DIC in patients with COVID-19 (last update: July 2020)

\begin{tabular}{|c|c|c|c|}
\hline DIC management & $\begin{array}{l}\text { Global COVID-19 } \\
\text { Thrombosis Collaborative } \\
\text { Group, Bikdeli et } \text { al }^{9}\end{array}$ & $\begin{array}{l}\text { Health System } \\
\text { Anticoagulation Task Force, } \\
\text { Watson et al }\end{array}$ & VAS \\
\hline $\begin{array}{l}\text { Panel of hematological } \\
\text { tests }\end{array}$ & $\begin{array}{l}\text { Platelet count, PT, D-dimers, } \\
\text { and fibrinogen }\end{array}$ & & $\begin{array}{l}\text { Platelet count, PT, D-dimers, } \\
\text { fibrinogen, AT, and PC } \\
\text { activity }\end{array}$ \\
\hline $\begin{array}{l}\text { Diagnostic tool for } \\
\text { compensated DIC }\end{array}$ & Not proposed & Not proposed & Compensated DIC-ISTH score \\
\hline $\begin{array}{l}\text { Frequency of } \\
\text { assessment for } \\
\text { compensated DIC }\end{array}$ & Not proposed & Not proposed & Every 1 or 2 days \\
\hline $\begin{array}{l}\text { Treatment for } \\
\text { compensated DIC }\end{array}$ & Not proposed & Not proposed & $\begin{array}{l}\text { - Intermediate dose of } \\
\text { LMWH. } \\
\text { - Therapeutic doses of } \\
\text { LMWH if the levels of D- } \\
\text { dimers continue to in- } \\
\text { crease (i.e., doubling of } \\
\text { D-dimer concentration } \\
\text { or D-dimer levels higher } \\
\text { than } 10,000 \mathrm{ng} / \mathrm{mL} \text { ). } \\
\text { - In severe AT deficiency } \\
\text { (<50\%) administration } \\
\text { of AT concentrate } \\
\text { should be considered. } \\
\text { - The bleeding risk needs } \\
\text { to be carefully } \\
\text { evaluated. }\end{array}$ \\
\hline $\begin{array}{l}\text { Diagnostic tool for } \\
\text { overt DIC }\end{array}$ & Overt DIC-ISTH score & Overt DIC-ISTH score & Overt DIC-ISTH score \\
\hline $\begin{array}{l}\text { Frequency of } \\
\text { assessment }\end{array}$ & Not proposed & Not addressed & Every 1 or 2 days \\
\hline Treatment of overt DIC & $\begin{array}{l}\text { - Addressing the underly- } \\
\text { ing hypoxia or coinfec- } \\
\text { tion. } \\
\text { - Transfusion thresholds } \\
\text { similar to those recom- } \\
\text { mended for other criti- } \\
\text { cally ill patients. } \\
\text { - If invasive procedures } \\
\text { are planned, prophylac- } \\
\text { tic transfusion of plate- } \\
\text { lets, fresh frozen } \\
\text { plasma, fibrinogen, and } \\
\text { prothrombin complex } \\
\text { concentrate may be } \\
\text { considered. } \\
\text { - Patients requiring tar- } \\
\text { geted temperature } \\
\text { management may ex- } \\
\text { hibit prolongations of } \\
\text { both PT and aPTT with- } \\
\text { out evidence of bleed- } \\
\text { ing diathesis. } \\
\text { Correction of coagulop- } \\
\text { athy in unselected } \\
\text { patients without overt } \\
\text { bleeding is not recom- } \\
\text { mended } \\
\text { LMWH prophylaxis may } \\
\text { decrease thrombin gen- } \\
\text { eration and modify the } \\
\text { course of DIC. }\end{array}$ & $\begin{array}{l}\text { - Prophylactic dose enox- } \\
\text { aparin if no contraindi- } \\
\text { cation exists. } \\
\text { - There is no role for } \\
\text { therapeutic anticoagu- } \\
\text { lation in DIC, in the ab- } \\
\text { sence of an acute } \\
\text { thrombotic event. } \\
\text { - There is no role for giv- } \\
\text { ing blood products to } \\
\text { correct laboratory ab- } \\
\text { normalities in the ab- } \\
\text { sence of bleeding. } \\
\text { - If bleeding occurs, } \\
\text { blood product(s) should } \\
\text { be given to replace the } \\
\text { depleted components. } \\
\text { - Factor VIla and pro- } \\
\text { thrombin complex con- } \\
\text { centrate use is } \\
\text { discouraged, as the risk } \\
\text { of serious thrombosis is } \\
\text { high. }\end{array}$ & $\begin{array}{l}\text { - Continuation of LMWH } \\
\text { or UFH (if severe renal } \\
\text { insufficiency) at doses } \\
\text { as in compensated DIC. } \\
\text { - AT concentrates i.v. to } \\
\text { maintain AT at normal } \\
\text { levels ( }>80 \% \text { ). } \\
\text { - If consumption coagul- } \\
\text { opathy progresses or } \\
\text { severe thrombocytope- } \\
\text { nia appears (platelet } \\
<25 \mathrm{G} / \mathrm{L} \text { ) and bleeding } \\
\text { diathesis is manifested, } \\
\text { heparin treatment must } \\
\text { be stopped and plasma } \\
\text { and platelet transfusion } \\
\text { should be considered. } \\
\text { - In the absence of } \\
\text { bleeding diathesis, } \\
\text { transfusion of plasma } \\
\text { and platelets is not rec- } \\
\text { ommended for the cor- } \\
\text { rection of the clotting } \\
\text { time and the increase of } \\
\text { platelet count, and con- } \\
\text { tinuation of heparin } \\
\text { treatment should } \\
\text { be considered after } \\
\text { correction of coagulop- } \\
\text { athy and thrombocyto- } \\
\text { penia (platelet }>50 \mathrm{G} / \mathrm{L} \text { ) }\end{array}$ \\
\hline
\end{tabular}


Table 6 (Continued)

\begin{tabular}{|c|c|c|c|}
\hline DIC management & 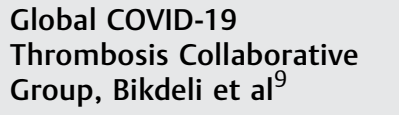 & $\begin{array}{l}\text { Health System } \\
\text { Anticoagulation Task Force, } \\
\text { Watson et al }\end{array}$ & VAS \\
\hline & $\begin{array}{l}\text { - For patients with mod- } \\
\text { erate or severe COVID- } \\
19 \text { and an indication for } \\
\text { dual-antiplatelet thera- } \\
\text { py (e.g., PCl within the } \\
\text { past } 3 \text { months or recent } \\
\text { MI) and with suspected } \\
\text { or confirmed DIC with- } \\
\text { out overt bleeding, } \\
\text { decisions for antiplate- } \\
\text { let therapy need to be } \\
\text { individualized. In gener- } \\
\text { al, it is reasonable to } \\
\text { continue dual-antiplate- } \\
\text { let therapy if platelet } \\
\text { count } \geq 50 \mathrm{G} / \mathrm{L} \text { and to } \\
\text { reduce to single-anti- } \\
\text { platelet therapy if } 25 \\
\mathrm{G} / \mathrm{L} \leq \text { platelet } \\
\text { count }<50 \mathrm{G} / \mathrm{L} \text { and dis- } \\
\text { continue if platelets } \\
<25 \mathrm{G} / \mathrm{L}\end{array}$ & & $\begin{array}{l}\text { re-initiation of LMWH at } \\
\text { prophylactic doses. } \\
\text { - Close monitoring of } \\
\text { anti-Xa activity and AT } \\
\text { levels. }\end{array}$ \\
\hline
\end{tabular}

Abbreviations: aPTT, activated partial thromboplastin time; AT, antithrombin; DIC, disseminated intravascular coagulation; ISTH, International Society on Thrombosis and Haemostasis; LMWH, low-molecular-weight heparin; MI, myocardial infarction; PC, protein C; PCI, percutaneous coronary intervention; PT, prothrombin time; UFH, unfractionated heparin.

ill patients, administration of tPA (25 mg intravenously over 2 hours, followed by a $25 \mathrm{mg}$ tPA infusion over the subsequent 22 hours) in mechanically ventilated COVID-19-positive patients resulted in a transient improvement of the respiratory capacity without any bleeding complications. ${ }^{157,158}$ The same therapeutic protocol was applied in five patients with COVID-19 and evolutive severe respiratory insufficiency who were not under mechanical ventilation and the results showed permanent improvement of their respiratory capacity. ${ }^{159}$

\section{VAS Recommendations for Management of Hypercoagulability, DIC, and Risk of Disease Worsening in Patients with Vascular Disease or Cardiovascular Risk Factors and COVID-19}

- Hypercoagulability is a frequent and early manifestation of coagulopathy in patients with COVID-19.

- Among the limited number of hypercoagulability biomarkers studied so far, an increase in D-dimer is correlated with the COVID-19 severity. However, D-dimers cannot be used as a "stand-alone" test in the management of COVID-19 patients.

- The most updated COVID-19 panel of hypercoagulability tests in patients with COVID-19 (COAG-COVID-19 panel) includes hemoglobin, platelet count, lymphocyte count, PT, aPTT, fibrinogen, D-dimer, AT activity, and PC activity.

- A RAM for disease worsening adapted for SARS-CoV-2 infection is an urgent need for prompt and targeted treatment of patients with COVID-19. The COMPASSCOVID-19 score responds to this objective but needs to be externally validated.

- The application of the COMPASS-COVID-19 RAM for evaluation of the risk for disease worsening can be considered in patients with VD-CVR and nonsevere COVID-19.

- The COAG-COVID-19 panel should be evaluated routinely and repeated every 1 or 2 days from hospital admission until hospital discharge. This diagnostic strategy provides global and dynamic information for the hypercoagulable state and its evolution during patients' trajectory.

- Consumption coagulopathy is not a frequent alteration in patients with COVID-19. Patients with COVID-19 do not present overt DIC unless hospitalization is complicated with sepsis.

- The compensated DIC-ISTH score rather than the overt DIC-ISTH score appears to be more compatible with the profile of hypercoagulability in hospitalized COVID-19 patients.

- The performance of other available scores for diagnosis of DIC in patients with COVID-19 needs to be evaluated in prospective studies.

- In patients with compensated DIC-ISTH score $\geq 5$, treatment with LMWH at intermediate doses should be considered. Therapeutic doses of LMWH should be considered if the levels of D-dimer continue to increase (i.e., doubling of D-dimer concentration or D-dimer levels higher than $10,000 \mathrm{ng} / \mathrm{mL}$ ). The bleeding risk needs to be carefully evaluated. 
- In the case of severe AT deficiency ( $<50 \%$ ), administration of AT concentrates should be considered.

- An overt DIC should be considered when the clotting times continue to prolong, and the fibrinogen concentration and platelet count continue to decrease.

- For the treatment of overt DIC without bleeding diathesis, the following steps should be considered:

- Maintain anticoagulant treatment with LMWH (or UFH in patients with severe renal insufficiency) at the same doses as in compensated DIC even if there is prolongation of PT and aPTT.

- In severe deficiency of AT ( $<50 \%$ AT activity), administration of AT concentrates should be considered aiming to maintain AT above the lower normal level (>80\%).

- In severe deficiency of PC ( $<50 \%$ PC activity), administration of PC concentrates should be considered aiming to maintain PC above the lower normal level $(>80 \%)$.

- If severe thrombocytopenia appears (platelet $<25 \mathrm{G} / \mathrm{L}$ ) or bleeding diathesis is manifested, anticoagulant treatment must be stopped until bleeding cessation and control. Plasma and/or platelet transfusions should be considered in the case of bleeding.

- In the absence of active bleeding, transfusion of plasma and/or platelets is not recommended for the correction of clotting times and an increase of platelet count. Continuation of heparin treatment should be considered.

- After correction of coagulopathy and thrombocytopenia (platelet count $>50 \mathrm{G} / \mathrm{L}$ ), reinitiation of $\mathrm{LMWH}$ at prophylactic doses should be resumed with a close monitoring of anti-Xa activity and AT levels.

\section{Risk of Venous Thromboembolism and Thromboprophylaxis in Patients with COVID-19}

Patients with COVID-19 are classified at high risk for VTE principally because of the disease characteristics (severe stage, enhanced inflammation, and hypercoagulability) and the frequent presence of inherent predisposing risk factors, particularly CVDs, cardiovascular risk factors (obesity, diabetes mellitus, arterial hypertension), or other underlying diseases.

The risk of VTE is recognized (1) during hospitalization at the conventional ward or ICU, (2) after hospital discharge in high-risk patients, and (c) in out-of-hospital settings, in patients with mild COVID-19 who receive home-based medical care.

The WHO, very early after pandemic declaration, has drawn attention to the vascular complications associated with COVID-19 infection. The interim guidance recommends thromboprophylaxis with either UFH or LMWH. ${ }^{160}$

LMWH is the first choice for VTE prevention in hospitalized COVID-19 patients and is recommended by the international guidelines published by groups of experts summarized in - Table 7. ${ }^{161-166}$

\section{Risk of VTE during Hospitalization of Patients with Vascular Disease or Cardiovascular Risk Factors and COVID-19}

COVID-19 is a major risk factor for VTE and the presence of additional risk factors in patients with COVID-19, such ICU hospitalization, immobilization, and prolonged hospitalization, further increases the risk of VTE. ${ }^{9,164,167}$

Pharmacological thromboprophylaxis with fixed prophylactic doses of LMWHs or fondaparinux is recommended in hospitalized acutely ill patients classified at high risk for VTE with an appropriate validated RAM in medical settings (IMPROVE or PADUA). ${ }^{168,169}$

The incidence of objectively confirmed VTE in hospitalized patients with COVID-19 has been consistently reported by several groups and varies from 3-15 to 7-50\% in conventional ward and ICU-hospitalized patients, respectively. ${ }^{147,170-176}$

The meta-analysis of these studies showed that the overall incidence of symptomatic, objectively confirmed VTE in hospitalized patients with COVID-19 was $22 \%$ (95\% CI: 11.2-34.9). The rate of VTE in ICU patients was $31 \%$ (95\% CI: 19.1-44.7). ${ }^{129}$ The classical rate of VTE in hospitalized patients in the medical ward was only $8.6 \%$ (95\% CI: 1.3-21.5). Nevertheless, there is a significant discrepancy of the VTE rate among the studies on patients with COVID-19 hospitalized either at the conventional board or at the ICU.

More than $75 \%$ of the patients enrolled in these studies were receiving pharmacological thromboprophylaxis with LMWH (either at a fixed dose as recommended for acutely ill medical patients or at a weight-adjusted dose). ${ }^{129}$ The phase III placebo-controlled clinical trials MEDENOX, PREVENT, and ARTEMIS showed that the incidence of asymptomatic VTE in hospitalized acutely ill medical patients who received thromboprophylaxis with enoxaparin, dalteparin, and fondaparinux was $5.5,5$, and $2.8 \%$, respectively. ${ }^{177-179}$ This figure is sticking lower to that observed in hospitalized patients who received LMWH thromboprophylaxis.

A retrospective multicenter observational study focused on the evaluation of the benefit-risk ratio of thromboprophylaxis with heparin in 400 hospitalized patients with COVID-19. The symptomatic objectively confirmed VTE rate was $4.8 \%$ (95\% CI: $2.9-7.3 \%$ ) and the overall thrombotic complication (including VTE, central vein catheter thrombosis, and continuous venovenous hemofiltration catheter) rate was 9.5\% (95\% CI: $6.8-12.8 \%){ }^{176}$ All patients were receiving anticoagulation with standard prophylactic doses of UFH or LMWH at the time of the event. The overall bleeding rate was $4.8 \%$ (95\% CI: $2.9-7.3 \%$ ). The rate of bleeding events was 3.1\% (95\% CI: $1.4-6.1 \%)$ in patients hospitalized at the conventional ward and $7.6 \%(95 \% \mathrm{CI}$ : 3.9-13.3\%) in ICU-patients. The major bleeding rate was $2.3 \%$ (95\% CI: $1.0-4.2 \%$ ). All but one major bleed occurred in the critically ill, for a rate of $5.6 \%$ (95\% CI: $2.4-10.7 \%$ ). Only three out of the 400 patients had an overt DIC (according to the respective ISTH score). Patients with thrombotic complications had higher D-dimer, fibrinogen, CRP, ferritin, and procalcitonin levels, while patients with bleeding 


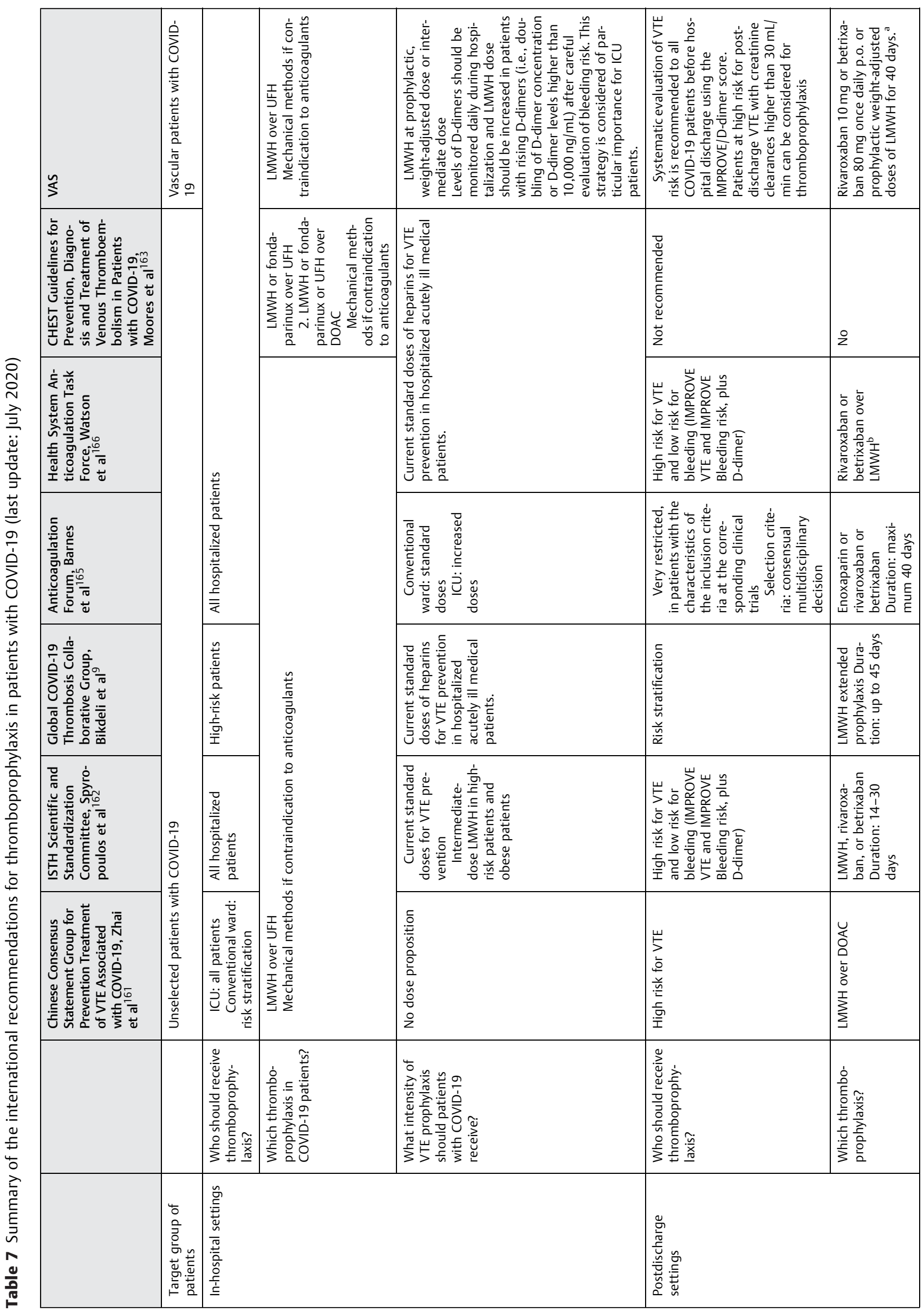




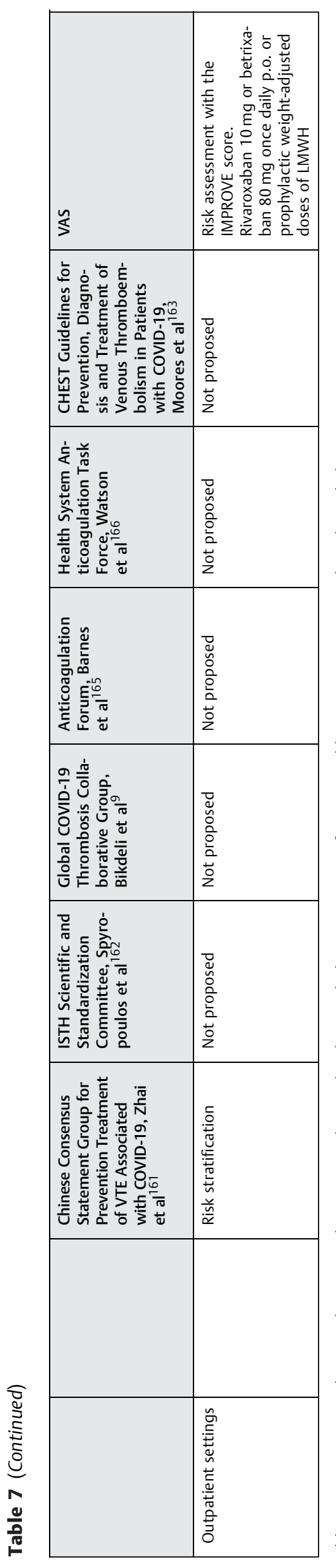

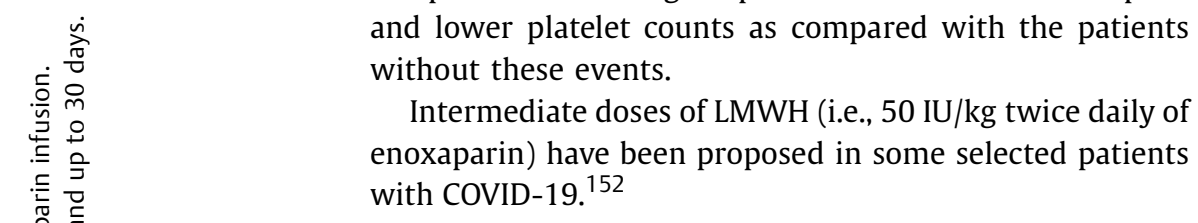

Protocols with intermediate or weight-adjusted doses of LMWH, particularly in obese patients, have been adopted in some centers. Guided modification of LMWH dose according to D-dimer levels' evolution or to the anti-Xa activity target in plasma (i.e., $0.4-0.8$ anti-Xa IU/mL measured 4 hours after the subcutaneous [s.c.] injection or trough levels at least 0.2 anti-Xa IU/mL) is a practice applied by some centers as well. However, the efficacy and safety of these practices has not been controlled. In addition, several methodological issues (i. e., post-hoc or unadjusted analysis, not clearly defined end points, or observational period, etc.) classify these studies at low quality of evidence. Nevertheless, these studies provide some signal for the elaboration of well-conducted prospective clinical trials to identify an optimal antithrombotic strategy.

The increase of D-dimer (a marker of fibrin degradation in vivo) indicates enhanced fibrin formation and is considered as an indirect marker of in vivo thrombin generation. However, in patients with COVID-19, the increase of D-dimer might be an indicator of the inflammatory reaction related to the cytokine storm. ${ }^{180}$ Theoretically, D-dimer levels should not be used as a stand-alone test for the guidance of the antithrombotic treatment. Nevertheless, until the time of the publication of this article the D-dimer is the only test which has been widely assessed for the evaluation of hypercoagulability in patients with COVID-19.

VAS strongly encourages studies aiming to identify accurate biomarkers of hypercoagulability in the evaluation of the efficacy of the antithrombotic treatment. VAS also encourages prospective studies for the derivation of accurate clinico-biological scores in the evaluation of the risk of resistance to the antithrombotic treatment in patients with COVID-19.

Indeed, 25 clinical trials, registered in ClinicalTrials.gov, are comparing the efficacy and safety of prophylactic and intermediate doses of LMWH for VTE prevention in hospitalized COVID19 patients. $^{181}$

\section{Post-Discharge Risk of VTE in Patients with Vascular Disease or Cardiovascular Risk Factors and COVID-19} Some of hospitalized patients with COVID-19 share common VTE risk factors with those hospitalized for severe acute medical illnesses, such as CVD and cardiovascular risk factors, elderly, obesity, or cancer. ${ }^{182}$

Studies in hospitalized acutely ill medical patients showed that the risk of VTE remains high after hospital discharge and identification of high VTE risk patients remains a challenging issue. ${ }^{183}$ Extended, post-hospital discharge thromboprophylaxis with LMWH (enoxaparin, tinzaparin, or dalteparin) or DOAC (rivaroxaban $10 \mathrm{mg}$ or betrixaban $80 \mathrm{mg}$ daily) has a favorable benefit/risk ratio when applied in high VTE risk patients. ${ }^{105,184}$ An IMPROVE 
D-dimer score $\geq 4$ combined with elevated D-dimer (greater than twofold the upper normal limit) identifies an over threefold higher VTE risk population requiring a prolonged prophylaxis. The addition of at least two clinical predictors among the predictors of age $>60$, a personal history of VTE, active cancer, or known thrombophilia is expected to further increase the sensitivity of the RAM to identify patients at high risk of post-hospital discharge VTE. These patients will benefit from extended thromboprophylaxis after hospital discharge with rivaroxaban $10 \mathrm{mg}$ or betrixaban $80 \mathrm{mg}$ once daily for up to 40 days without an increase in major bleeding. ${ }^{185-188}$

\section{VTE Risk in Out-of-Hospital Medical Care of Patients with Vascular Disease or Cardiovascular Risk Factors and COVID-19}

During the epidemic waves, hospitals are overcrowded and patients with mild or even moderate COVID-19 receive health care at home. Some of them are at high risk for VTE at least during the bedridden period. These patients should be promptly identified using the IMPROVE or the PADUA scores and receive pharmacological thromboprophylaxis in the absence of contraindication or any risk factor for bleeding. ${ }^{168,189}$ A prophylactic dose of LMWH, or rivaroxaban $10 \mathrm{mg}$, or betrixaban $80 \mathrm{mg}$ once daily could be considered for thromboprophylaxis in high VTE risk COVID-19 outpatients. Rivaroxaban $10 \mathrm{mg}$ or betrixaban $80 \mathrm{mg}$ once daily is proposed because they are those among the DOACs that have been studied in the context of thromboprophylaxis in acutely ill medical patients. Oral administration of rivaroxaban and betrixaban has a significant advantage over LMWH use in this setting, in the absence of any potential drug interference or severe renal impairment, because it combines patients' comfort and no exposure to contamination risk for nurses.

\section{VAS Statement for the Management of VTE Risk in} Patients with VD-CVR and COVID-19

Thromboprophylaxis with LMWH or UFH (at the recommended doses for acutely ill medical patients) has been administered in the majority of hospitalized patients with COVID-19 enrolled in the reported studies on VTE incidence and seen in this section. However, in most of these studies, the rate of VTE in hospitalized patients either in conventional wards or in ICUs was at least twofold higher as compared with the respective rates reported in phase III clinical trials in acutely ill medical patients.

VAS experts acknowledge that for methodological reasons a direct comparison between the two settings is not feasible. Nevertheless, the high rate of VTE in hospitalized patients with COVID-19 underlines the need for more intense thromboprophylaxis at least for some patients who are at obvious higher risk.

VAS experts consider that more intense pharmacological thromboprophylaxis is applicable particularly in patients with VR-CVR and COVID-19. Indeed, they present cardiovascular risk factors and/or diseases which are also significant risk factors for VTE. Moreover, patients with vascular disease are older and may be more frequently obese as compared with the nonvascular ones. Nevertheless, for the same reasons a careful evaluation of the bleeding risk is strongly recommended.

- Table 6 compares the guidelines proposed by six international groups of experts for the prevention of VTE in patients with COVID-19. VAS experts based on these guidelines proposed a strategy adapted for patients with vascular disease according to the rationale presented in the paragraph above.

\section{Treatment of VTE in Patients with Vascular Disease or Cardiovascular Risk Factors Hospitalized with COVID-19}

For hospitalized patients with VD-CVR and COVID-19, VAS endorses the recommendations of the ISTH Scientific Subcommittee for diagnosis and treatment of VTE. The recommendations of the international groups of experts for the treatment of VTE in patients with COVID-19 are summarized in - Table 8.

\section{VAS Recommendations for Thromboprophylaxis in Patients with Vascular Disease and COVID-19}

Thromboprophylaxis in Hospitalized Patients with COVID-19

- Hospitalized patients with vascular disease and COVID-19 are at high risk for VTE. LMWH at a prophylactic, weightadjusted dose or an intermediate dose, in the absence of contraindications or active bleeding, is recommended for all patients including those with moderate renal insufficiency (creatinine clearance $\geq 30 \mathrm{~mL} / \mathrm{min}$ ), upon admission until hospital discharge.

- In patients with contraindications for antithrombotic treatment, the use of mechanical measures for thromboprophylaxis (i.e., compression stocking, foot-pump) is recommended. The use of removable vena cava filters for the prevention of VTE is not recommended. In the case of patients at very high risk of VTE with absolute contraindication to the antithrombotic treatment, the use of removable vena cava filters could be considered for primary VTE prevention. This decision must be taken consensually by a group of experts including a vascular specialist.

- Obese patients (BMI > 30) are at higher risk of VTE and also at high risk of COVID-19 worsening. Intermediate doses adapted according to the body weight should be considered.

- In patients with severe renal failure (creatinine clearance $<30 \mathrm{~mL} / \mathrm{min}$ ), UFH is the first option for thromboprophylaxis. Due to the high frequency of heparin resistance, the LMWH tinzaparin or dalteparin (which show limited accumulation in this context) at a weightadjusted dose can be considered instead of UFH. In this case, peak and/or trough levels of anti-Xa activity in plasma should be monitored and the dose should be adapted to avoid any drug accumulation. 


\begin{tabular}{|c|c|c|}
\hline 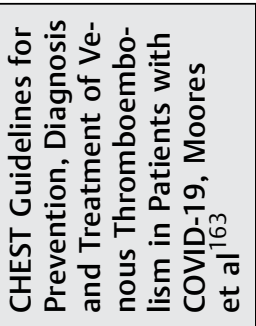 & 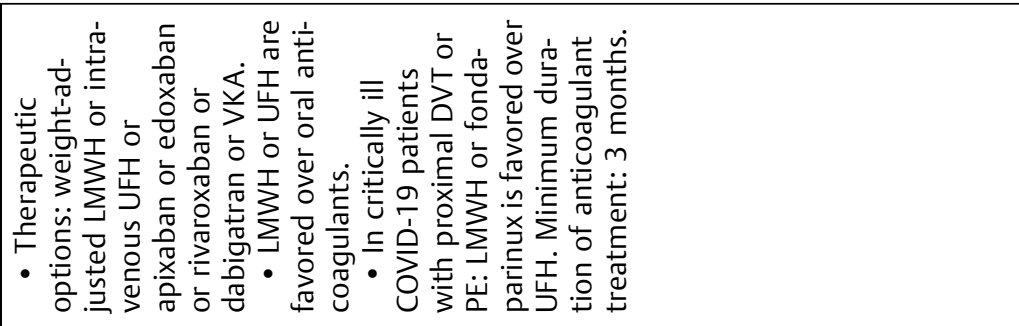 & 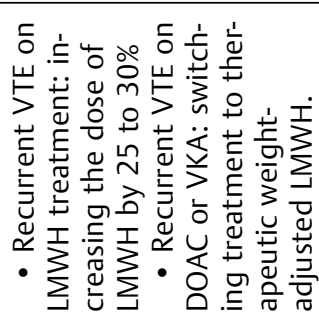 \\
\hline 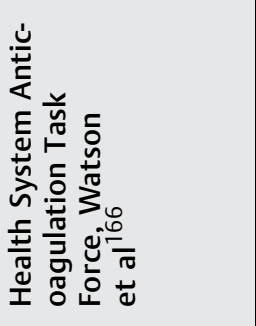 & 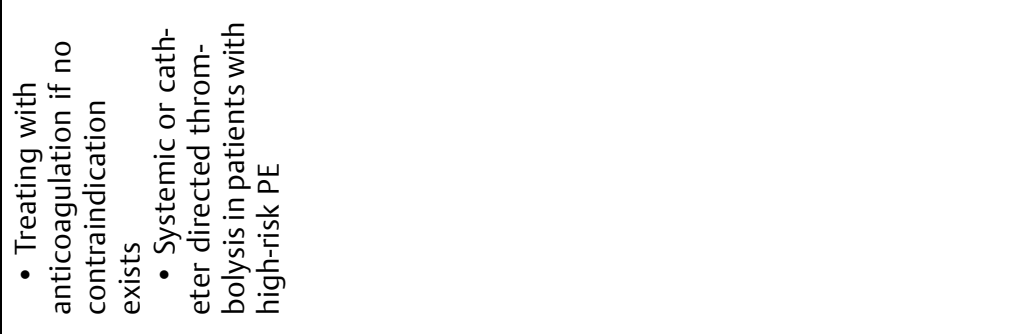 & 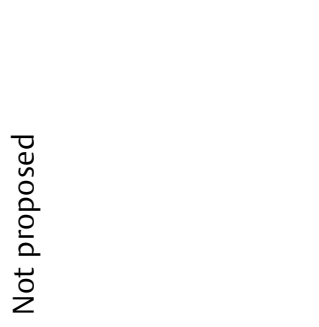 \\
\hline 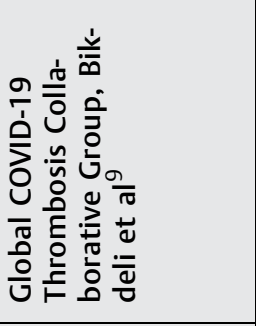 & 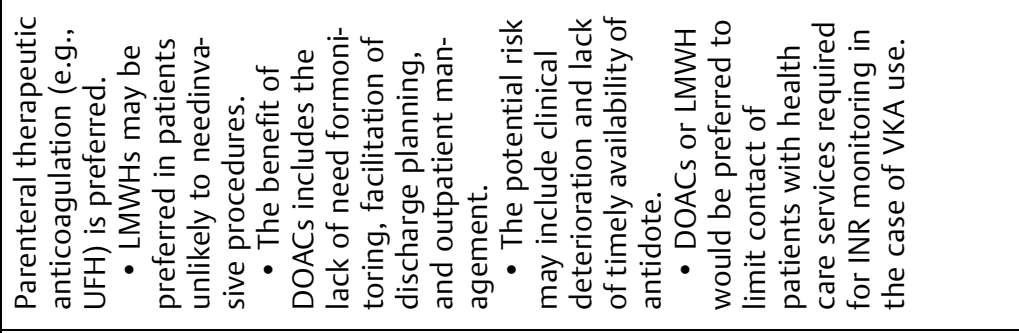 & 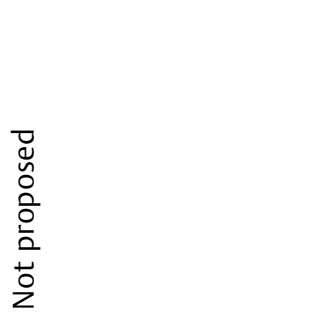 \\
\hline 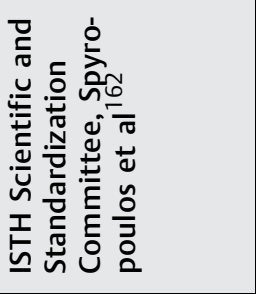 & 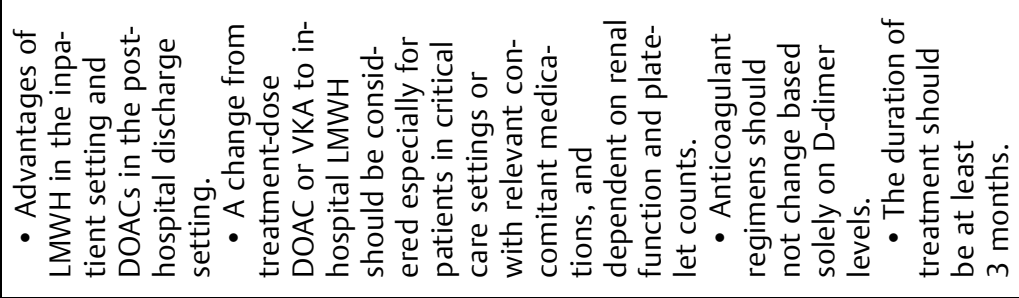 & 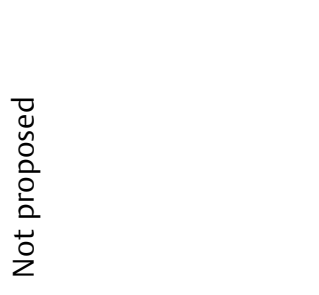 \\
\hline 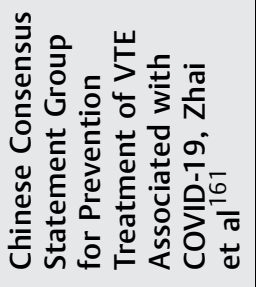 & 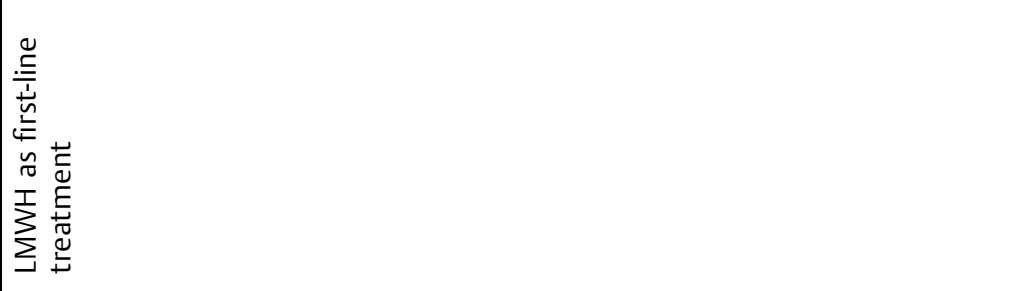 & \\
\hline & 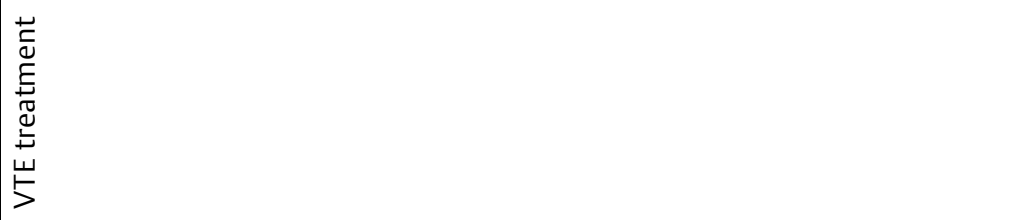 & 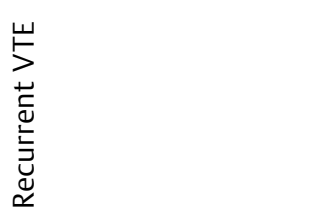 \\
\hline
\end{tabular}

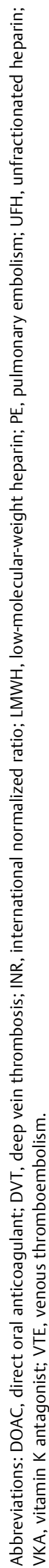




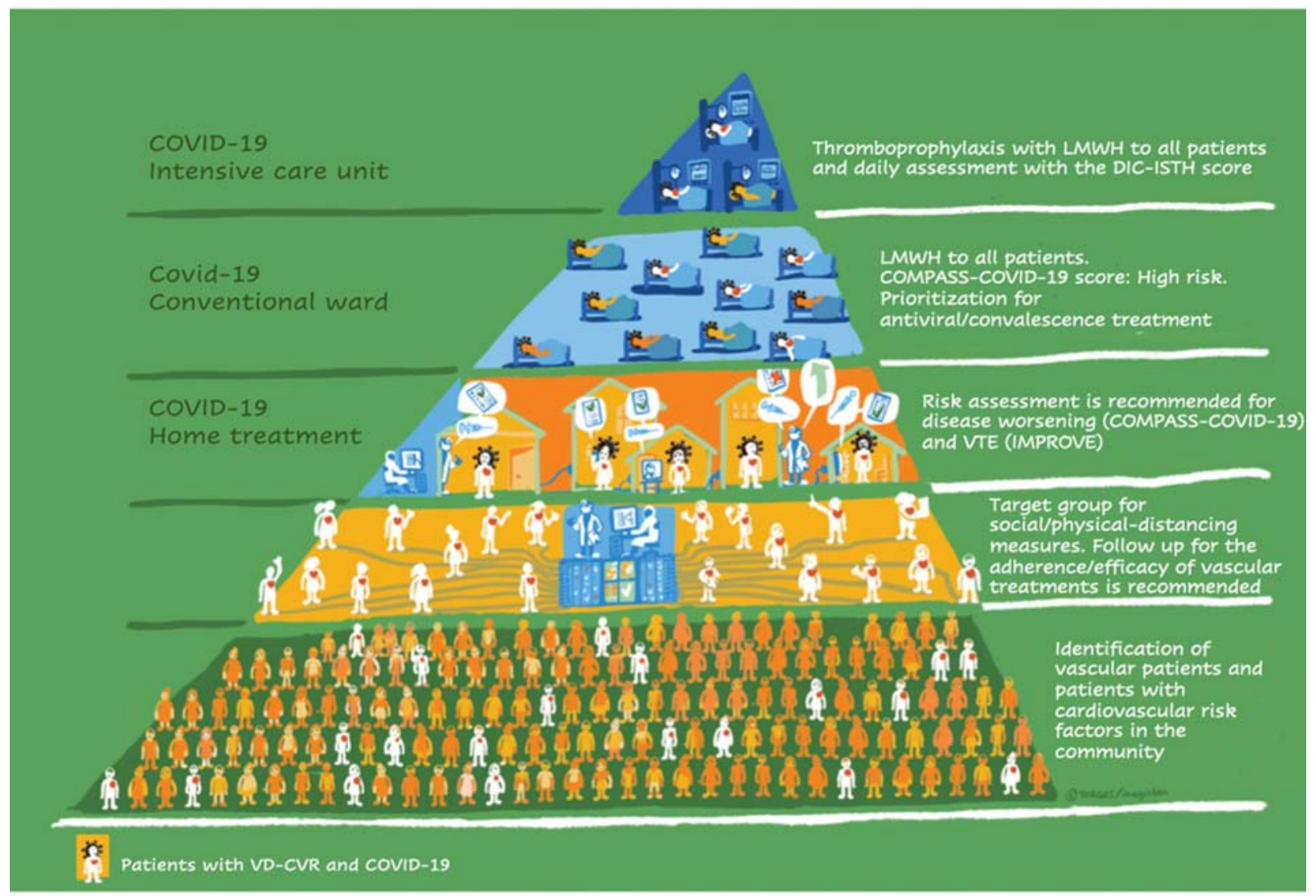

Fig. 3 Integral strategy recommended by VAS for the management of patients with vascular disease or cardiovascular risk factors (VD-CVR) to prevent SARS-CoV-2 infection and to decrease the risk of COVID-19 worsening and manifestation of vascular complications during patients' trajectory.

- Levels of D-dimer should be monitored daily during hospitalization and the dose of LMWH should be increased to therapeutic levels in patients with important rising D-dimer (i.e., doubling of D-dimer concentration or D-dimer levels higher than $10,000 \mathrm{ng} / \mathrm{mL}$ ) after careful evaluation of bleeding risk. This strategy is considered to be of particular importance for ICU patients.

- Exploration of VTE with imaging methods could be considered in patients with a sharp increase of D-dimer.

- VAS strongly encourages studies aiming to identify accurate biomarkers of hypercoagulability in the evaluation of the efficacy of the antithrombotic treatment. VAS also encourages prospective studies for the derivation of clinico-biological scores accurate in the evaluation of the risk of resistance to the antithrombotic treatment in patients with COVID-19.

\section{Thromboprophylaxis after Hospital Discharge}

- Systematic evaluation of VTE risk is recommended to all COVID-19 patients before hospital discharge using the IMPROVE D-dimer score.

- Patients at high VTE risk after discharge with creatinine clearance $\geq 30 \mathrm{~mL} / \mathrm{min}$ can be considered for thromboprophylaxis with rivaroxaban $10 \mathrm{mg}$ or betrixaban $80 \mathrm{mg}$ once daily p.o. (orally) or prophylactic weight-adjusted doses of LMWH for 40 days.

\section{Thromboprophylaxis in Patients Receiving Medical Care} at Home

- Patients with VD-CVR and COVID-19 who receive health care at home or in nonhospital settings (i.e., retirement home) should be assessed for VTE risk using the IMPROVE score.

- Patients at high risk for VTE with creatinine clearance $\geq 30 \mathrm{~mL} / \mathrm{min}$ can be considered for thromboprophylaxis with rivaroxaban $10 \mathrm{mg}$ or betrixaban $80 \mathrm{mg}$ once daily or LMWH at prophylactic weight-adjusted doses.

- Rivaroxaban and betrixaban present some practical advantages over LMWH, one among them is the simpler administration mode, which does not require nurse visits. Consequently, there is no risk of exposure of health care staff with contamination risk. Oral administration may improve patients' adherence to thromboprophylaxis.

- In the case that the patient receives home treatment with antiviral or other drugs that may alter the pharmacokinetics of DOACs, thromboprophylaxis with LMWH should be considered as the first-line treatment.

\section{Summary}

The clinical and epidemiological data and the available evidence from autopsy studies document that hypercoagulability, endothelial cell activation, and massive inflammation are major pathways leading to worsening of COVID-19 and death of patients. 
Immunothrombosis in lung microcirculation or in other organs (kidneys, liver, heart, brain, and intestine) and VTE are frequent in patients with severe COVID-19 and critical illness. Arterial thrombosis is an additional vascular complication in patients with COVID-19.

The experts of the VAS-European Independent Foundation in Angiology/Vascular Medicine elaborated an integral strategy for the management of patients with VD-CVR and COVID-19 since they are the largest cluster of patients at risk of disease worsening. This strategy is schematically represented in - Fig. 3.

Patients with vascular disease or cardiovascular risk factors need to be at the epicenter for the protection of SARS$\mathrm{CoV}-2$ infection at the level of primary health care system, because they are at a higher risk of disease worsening, VTE, and post-hospital discharge morbidity.

The recommendations of VAS for patients with VD-CVR are organized as follows:

- At the level of primary health care system, there is an urgent need to organize a medical network, including eHealth technologies, aiming the management of patients with VD-CVR during SARS-CoV-2 epidemic.

- Management of patients with VD-CVR and nonsevere COVID-19 receiving home-based medical care.

- Management of patients with VD-CVR hospitalized for COVID-19.

- Prevention of post-hospital discharge VTE in patients with VD-CVR and COVID-19.

It is evident that the antithrombotic treatment is an integral part of the therapeutic strategies for COVID-19. Beyond the prevention and treatment of VTE and the control of the hypercoagulable state, the antithrombotic agents together with drugs that downregulate the endothelial cell activation are expected to get a central place in the management of SARS-CoV-2 infection. The elaboration of prospective clinical trials for the evaluation of the safety, efficacy, and optimal use of the therapeutic strategies based on antithrombotic agents and drugs targeting the endothelium in patients with COVID-19 as recommended by the Global COVID-19 Thrombosis Collaborative Group is endorsed by the VAS experts. ${ }^{190}$

VAS with this guidance document wishes to help public health authorities in the design of targeted protection policies for vulnerable patients.

Vascular diseases are noncommunicable diseases and VAS is in favor of future efforts to identify general integrated measures for chronic disease, suitable to be detailed into more specialistic indication.

Acknowledging that due to the limited clinical experience in patients with COVID-19 and the absence of randomized clinical trials controlling the efficacy and safety of various antithrombotic treatment regiments and other interventions, the ensemble of the proposed recommendations has a low grade of evidence and will be updated as soon as the results of the ongoing clinical trials will be published.

\section{What is known about this topic?}

- SARS-CoV-2 infection induces endothelial cell activation, hypercoagulability, and enhanced inflammatory reaction.

- Immunothrombosis is a major contributor in the COVID-19 worsening process.

- Males, citizens with obesity, diabetes mellitus, or arterial hypertension, and patients with cardiovascular disease are at high risk for severe COVID-19.

\section{What does this paper add?}

- VAS proposes a COVID-19-oriented primary health care network for patients with vascular disease and cardiovascular risk factors (VD-CVR).

- Adherence to the antihypertensive, antiplatelet, antidiabetic, and lipid-lowering treatment and prevention of VTE are essential for the decrease of the risk for COVID-19 worsening in patients with VD-CVR.

- For hospitalized patients with VD-CVR and COVID-19, VAS recommends early administration of thromboprophylaxis with an intermediate dose of LMWH or UFH and a regular evaluation of the biological efficacy of the treatment.

Funding

None.

Conflict of Interest

None declared.

Acknowledgment

The authors are thankful to Yorgos Konstantinou (imagistan.com) for designing the visuals.

\section{References}

1 Cui J, Li F, Shi ZL. Origin and evolution of pathogenic coronaviruses. Nat Rev Microbiol 2019;17(03):181-192

2 Wu F, Zhao S, Yu B et al. A new coronavirus associated with human respiratory disease in China. Nature 2020;579(7798): 265-269

3 Lu R, Zhao X, Li J et al. Genomic characterisation and epidemiology of 2019 novel coronavirus: implications for virus origins and receptor binding. Lancet 2020;395(10224):565-574

4 Wan Y, Shang J, Graham R, Baric RS, Li F. Receptor recognition by novel coronavirus from Wuhan: an analysis based on decadelong structural studies of SARS. J Virol 2020;94(07):e00127-20

5 World Health Organization. Clinical management of severe acute respiratory infection (SARI) when COVID-19 disease is suspected -interim guidance, March 13, 2020 . Accessed July 26, 2020 at: https://www.who.int/publications/i/item/clinical-management-of-covid-19

6 Chen N, Zhou M, Dong X et al. Epidemiological and clinical characteristics of 99 cases of 2019 novel coronavirus pneumonia in Wuhan, China: a descriptive study. Lancet 2020;395 (10223):507-513 
7 Terpos E, Ntanasis-Stathopoulos I, Elalamy I et al. Hematological findings and complications of COVID-19. Am J Hematol 2020;95 (07):834-847

8 Maglakelidze N, Manto KM, Craig TJA. A review: does complement or the contact system have a role in protection or pathogenesis of COVID-19? Pulm Ther 2020;6(02):169-176

9 Bikdeli B, Madhavan MV, Jimenez D et al. COVID-19 and thrombotic or thromboembolic disease: implications for prevention, antithrombotic therapy, and follow-up: JACC state-of-the-art review. J Am Coll Cardiol 2020;75(23):2950-2973

10 Huang C, Wang Y, Li X et al. Clinical features of patients infected with 2019 novel coronavirus in Wuhan, China. Lancet 2020;395 (10223):497-506

11 Richardson S, Hirsch JS, Narasimhan Met aland the Northwell COVID-19 Research Consortium. Presenting characteristics, comorbidities, and outcomes among 5700 patients hospitalized with COVID-19 in the New York City Area. JAMA 2020;323(20): 2052-2059

12 Auld SC, Caridi-Scheible M, Blum JM et al. ICU and ventilator mortality among critically ill adults with coronavirus disease 2019. Crit Care Med 2020. Doi: 10.1097/CCM.0000000000004457

13 Driggin E, Madhavan MV, Bikdeli B et al. Cardiovascular considerations for patients, health care workers, and health systems during the COVID-19 pandemic. J Am Coll Cardiol 2020;75(18): 2352-2371

14 Bangash MN, Patel J, Parekh D. COVID-19 and the liver: little cause for concern. Lancet Gastroenterol Hepatol 2020;5(06): 529-530

15 Mehta P, McAuley DF, Brown M, Sanchez E, Tattersall RS, Manson JJHLH Across Speciality Collaboration, UK. COVID-19: consider cytokine storm syndromes and immunosuppression. Lancet 2020;395(10229):1033-1034

16 Gimbrone MA Jr, García-Cardeña G. Endothelial cell dysfunction and the pathobiology of atherosclerosis. Circ Res 2016;118(04): 620-636

17 Roth GA, Johnson C, Abajobir A et al. Global, regional, and national burden of cardiovascular diseases for 10 causes, 1990 to 2015. J Am Coll Cardiol 2017;70(01):1-25

18 Hamming I, Timens W, Bulthuis ML, Lely AT, Navis G, van Goor H. Tissue distribution of ACE2 protein, the functional receptor for SARS coronavirus. A first step in understanding SARS pathogenesis. J Pathol 2004;203(02):631-637

19 Hoffmann M, Kleine-Weber H, Schroeder S et al. SARS-CoV-2 cell entry depends on ACE2 and TMPRSS2 and is blocked by a clinically proven protease inhibitor. Cell 2020;181(02):271. e8-280.e8

20 Vaarala MH, Porvari KS, Kellokumpu S, Kyllönen AP, Vihko PT. Expression of transmembrane serine protease TMPRSS2 in mouse and human tissues. J Pathol 2001;193(01):134-140

21 Song WC, FitzGerald GA. COVID-19, microangiopathy, hemostatic activation, and complement. J Clin Invest 2020;140183; 140183

22 Aimes RT, Zijlstra A, Hooper JD et al. Endothelial cell serine proteases expressed during vascular morphogenesis and angiogenesis. Thromb Haemost 2003;89(03):561-572

23 Du L, Kao RY, Zhou Y et al. Cleavage of spike protein of SARS coronavirus by protease factor $\mathrm{Xa}$ is associated with viral infectivity. Biochem Biophys Res Commun 2007;359(01):174-179

24 Yang H, Xie W, Xue X et al. Design of wide-spectrum inhibitors targeting coronavirus main proteases. PLoS Biol 2005;3(10): e324

25 Biembengut ÍV, de Souza TACB. Coagulation modifiers targeting SARS-CoV-2 main protease Mpro for COVID-19 treatment: an in silico approach. Mem Inst Oswaldo Cruz 2020;115:e200179

26 Eleftheriou P, Amanatidou D, Petrou A, Geronikaki A. In silico evaluation of the effectivity of approved protease inhibitors against the main protease of the novel SARS-CoV-2 virus. Molecules 2020;25(11):E2529
27 Liu J, Li J, Arnold K, Pawlinski R, Key NS. Using heparin molecules to manage COVID-2019. Res Pract Thromb Haemost 2020;4(04): 518-523

28 Partridge LJ, Green LR, Monk PN. Unfractionated heparin potently inhibits the binding of SARS-CoV-2 spike protein to a human cell line. bioRxiv 2020. Doi: 10.1101/2020.05.21.107870

29 Mezger M, Nording H, Sauter R et al. Platelets and immune responses during thromboinflammation. Front Immunol 2019; 10:1731

30 Colman RW, Schmaier AH. Contact system: a vascular biology modulator with anticoagulant, profibrinolytic, antiadhesive, and proinflammatory attributes. Blood 1997;90(10):3819-3843

31 Maas C, Renné T. Coagulation factor XII in thrombosis and inflammation. Blood 2018;131(17):1903-1909

32 Baker CJ, Smith SA, Morrissey JH. Polyphosphate in thrombosis, hemostasis, and inflammation. Res Pract Thromb Haemost 2018; 3(01):18-25

33 Zuo Y, Yalavarthi S, Shi H. Neutrophil extracellular traps in COVID-19. JCI Insight 2020;5(11):e138999

34 Zuo Y, Zuo M, Yalavarthi S et al. Neutrophil extracellular traps and thrombosis in COVID-19. medRxiv 2020;48(09):1358-1364

35 Iba T, Levy JH, Levi M, Connors JM, Thachil J. Coagulopathy of coronavirus disease 2019. Crit Care Med 2020;48(09): 1358-1364

36 Zhang Y, Xiao M, Zhang S et al. Coagulopathy and antiphospholipid antibodies in patients with Covid-19. N Engl J Med 2020; 382(17):e38

37 Galeano-Valle F, Oblitas CM, Ferreiro-Mazón MM et al. Antiphospholipid antibodies are not elevated in patients with severe COVID-19 pneumonia and venous thromboembolism. Thromb Res 2020;192:113-115

38 Pons S, Fodil S, Azoulay E, Zafrani L. The vascular endothelium: the cornerstone of organ dysfunction in severe SARS-CoV-2 infection. Crit Care 2020;24(01):353

39 Khider L, Gendron N, Goudot G et al Curative anticoagulation prevents endothelial lesion in COVID-19 patients. J Thromb Haemost 2020. Doi: 10.1111/jth.14968

40 Nunes Duarte-Neto A, de Almeida Monteiro RA, da Silva LFF et al. Pulmonary and systemic involvement of COVID-19 assessed by ultrasound-guided minimally invasive autopsy. Histopathology 2020;77(02):186-197

41 Ackermann M, Verleden SE, Kuehnel M et al. Pulmonary vascular endothelialitis, thrombosis, and angiogenesis in Covid-19. N Engl J Med 2020;383(02):120-128

42 Fox SE, Akmatbekov A, Harbert JLet al. Pulmonary and cardiac pathology in African American patients with COVID-19: an autopsy series from New Orleans. Lancet Respir Med 2020;8 (07):681-686

$43 \mathrm{Wu} \mathrm{JH}, \mathrm{Li} \mathrm{X}$, Huang B et al. Pathological changes of fatal coronavirus disease 2019 (COVID-19) in the lungs: report of 10 cases by postmortem needle autopsy [in Chinese]. Zhonghua Bing Li Xue Za Zhi 2020;49(06):568-575

44 Carsana L, Sonzogni A, Nasr A et al. Pulmonary post-mortem findings in a series of COVID-19 cases from northern Italy: a twocentre descriptive study. Lancet Infect Dis 2020. Doi: 10.1016/ S1473-3099(20)30434-5

45 Varga Z, Flammer AJ, Steiger P et al. Endothelial cell infection and endotheliitis in COVID-19. Lancet 2020;395(10234):1417-1418

46 Fogarty H, Townsend L, Ni Cheallaigh C et al. More on COVID-19 coagulopathy in Caucasian patients. Br J Haematol 2020;189 (06):1060-1061

47 van Dam LF, Kroft LJM, van der Wal LI et al. Clinical and computed tomography characteristics of COVID-19 associated acute pulmonary embolism: a different phenotype of thrombotic disease? Thromb Res 2020;193:86-89

48 Danzi GB, Loffi M, Galeazzi G, Gherbesi E. Acute pulmonary embolism and COVID-19 pneumonia: a random association? Eur Heart J 2020;41(19):1858 
49 Du Y, Tu L, Zhu P et al. Clinical features of 85 fatal cases of COVID19 from Wuhan. A retrospective observational study. Am J Respir Crit Care Med 2020;201(11):1372-1379

50 Menter T, Haslbauer JD, Nienhold R et al. Postmortem examination of COVID-19 patients reveals diffuse alveolar damage with severe capillary congestion and variegated findings in lungs and other organs suggesting vascular dysfunction. Histopathology 2020;77(02):198-209

51 Lang M, Som A, Mendoza DP et al. Hypoxaemia related to COVID19: vascular and perfusion abnormalities on dual-energy CT. Lancet Infect Dis 2020;20(12):1365-1366

52 Sharma P, Uppal NN, Wanchoo R et al. COVID-19-associated kidney injury: a case series of kidney biopsy findings. J Am Soc Nephrol 2020;31(09):1948-1958

53 Edler C, Schröder AS, Aepfelbacher $M$ et al. Dying with SARSCoV-2 infection-an autopsy study of the first consecutive 80 cases in Hamburg, Germany. Int J Legal Med 2020. Doi: 10.1007/ s00414-020-02317-w

54 Calabrese F, Pezzuto F, Fortarezza F et al. Pulmonary pathology and COVID-19: lessons from autopsy. The experience of European Pulmonary Pathologists. Virchows Arch 2020. Doi: 10.1007/ s00428-020-02886-6

55 Fried JA, Ramasubbu K, Bhatt $R$ et al. The variety of cardiovascular presentations of COVID-19. Circulation 2020;141(23):1930-1936

56 Xu Z, Shi L, Wang Y et al. Pathological findings of COVID-19 associated with acute respiratory distress syndrome. Lancet Respir Med 2020;8(04):420-422

57 Liu Y, Yang Y, Zhang C et al. Clinical and biochemical indexes from 2019-nCoV infected patients linked to viral loads and lung injury. Sci China Life Sci 2020;63(03):364-374

58 Long B, Brady WJ, Koyfman A, Gottlieb M. Cardiovascular complications in COVID-19. Am J Emerg Med 2020;38(07):1504-1507

59 Zheng Z, Peng F, Xu B et al. Risk factors of critical \& mortal COVID19 cases: a systematic literature review and meta-analysis. J Infect 2020;81(02):e16-e25

60 Ruan Q Yang K, Wang W et al. Clinical predictors of mortality due to COVID-19 based on an analysis of data of 150 patients from Wuhan, China. Intensive Care Med 2020;46(05):846-848

61 Khurshid S, Choi SH, Weng LC et al. Frequency of cardiac rhythm abnormalities in a half million adults. Circ Arrhythm Electrophysiol 2018;11(07):e006273

62 Li B, Yang J, Zhao F et al. Prevalence and impact of cardiovascular metabolic diseases on COVID-19 in China. Clin Res Cardiol 2020; 109(05):531-538

$63 \mathrm{Wu}$ Z, McGoogan JM. Characteristics of and important lessons from the coronavirus disease 2019 (COVID-19) outbreak in China: summary of a report of 72314 cases from the Chinese Center for Disease Control and Prevention. JAMA 2020;323(13): $1239-1242$

64 Zheng Z, Peng F, Xu B et al. Risk factors of critical \& mortal COVID19 cases: a systematic literature review and meta-analysis. J Infect 2020;81(02):e16-e25

65 Roncon L, Zuin M, Rigatelli G, Zuliani G. Diabetic patients with COVID-19 infection are at higher risk of ICU admission and poor short-term outcome. J Clin Virol 2020;127:104354

66 Cohen G, Riahi Y, Alpert E, Gruzman A, Sasson S. The roles of hyperglycaemia and oxidative stress in the rise and collapse of the natural protective mechanism against vascular endothelial cell dysfunction in diabetes. Arch Physiol Biochem 2007;113(45):259-267

67 Zhu L, She ZG, Cheng X et al. Association of blood glucose control and outcomes in patients with COVID-19 and pre-existing Type 2 diabetes. Cell Metab 2020;31(06):1068-1077

68 Olinic DM, Spinu M, Olinic M et al. Epidemiology of peripheral artery disease in Europe: VAS educational paper. Int Angiol 2018; 37(04):327-334
69 Zierfuss B, Catalano M, Schernthaner GH. Finally, the big picture of morbidity and mortality in peripheral arterial disease? Atherosclerosis 2020;293:92-93

70 Bellosta R, Luzzani L, Natalini G et al. Acute limb ischemia in patients with COVID-19 pneumonia. J Vasc Surg 2020;72(06): 1864-1872

71 Perini P, Nabulsi B, Massoni CB, Azzarone M, Freyrie A. Acute limb ischaemia in two young, non-atherosclerotic patients with COVID-19. Lancet 2020;395(10236):1546

72 Cantador E, Núñez A, Sobrino P et al. Incidence and consequences of systemic arterial thrombotic events in COVID-19 patients. J Thromb Thrombolysis 2020;50(03):543-547

73 Klok FA, Kruip MJHA, van der Meer NJM et al. Confirmation of the high cumulative incidence of thrombotic complications in critically ill ICU patients with COVID-19: an updated analysis. Thromb Res 2020;191:148-150

74 Lodigiani C, Iapichino G, Carenzo Let al;Humanitas COVID-19 Task Force. Venous and arterial thromboembolic complications in COVID-19 patients admitted to an academic hospital in Milan, Italy. Thromb Res 2020;191:9-14

75 Suchonwanit P, Leerunyakul K, Kositkuljorn C. Cutaneous manifestations in COVID-19: lessons learned from current evidence.J Am Acad Dermatol 2020;83(01):e57-e60

76 Recalcati S. Cutaneous manifestations in COVID-19: a first perspective. J Eur Acad Dermatol Venereol 2020;34(05): e212-e213

77 Estébanez A, Pérez-Santiago L, Silva E, Guillen-Climent S, GarcíaVázquez A, Ramón MD. Cutaneous manifestations in COVID-19: a new contribution. J Eur Acad Dermatol Venereol 2020;34(06): e250-e251

$78 \mathrm{Su}$ CJ, Lee CH. Viral exanthem in COVID-19, a clinical enigma with biological significance. J Eur Acad Dermatol Venereol 2020;34 (06):e251-e252

79 Mahé A, Birckel E, Krieger S, Merklen C, Bottlaender L. A distinctive skin rash associated with coronavirus disease 2019? J Eur Acad Dermatol Venereol 2020;34(06):e246-e247

80 Henry D, Ackerman M, Sancelme E, Finon A, Esteve E. Urticarial eruption in COVID-19 infection. J Eur Acad Dermatol Venereol 2020;34(06):e244-e245

81 Zulfiqar AA, Lorenzo-Villalba N, Hassler P, Andrès E. Immune thrombocytopenic purpura in a patient with Covid-19. N Engl J Med382(18):e43

82 Alramthan A, Aldaraji W. Two cases of COVID-19 presenting with a clinical picture resembling chilblains: first report from the Middle East. Clin Exp Dermatol 2020;45(06):746-748

83 Kolivras A, Dehavay F, Delplace D et al. Coronavirus (COVID-19) infection-induced chilblains: a case report with histopathologic findings. JAAD Case Rep 2020;6(06):489-492

84 Manalo IF, Smith MK, Cheeley J, Jacobs R. A dermatologic manifestation of COVID-19: transient livedo reticularis. J Am Acad Dermatol 2020;83(02):700

85 Nyssen A, Benhadou F, Magnée M, André J, Koopmansch C, Wautrecht JC. Chilblains. Vasa 2020;49(02):133-140

86 Colmenero I, Santonja C, Alonso-Riaño M et al. SARS-CoV-2 endothelial infection causes COVID-19 chilblains: histopathological, immunohistochemical and ultraestructural study of 7 paediatric cases. Br J Dermatol 2020;183(04):729-737

87 Bae YS, Kim KH, Choi SW et al. Information technology-based management of clinically healthy COVID-19 patients: lessons from a living and treatment support center operated by seoul national university hospital. J Med Internet Res 2020;22(06):e19938

88 Fareed J, Hoppensteadt DA, Bick RL. An update on heparins at the beginning of the new millennium. Semin Thromb Hemost 2000; 26(Suppl 1):5-21

89 Darien BJ, Fareed J, Centgraf KS et al. Low molecular weight heparin prevents the pulmonary hemodynamic and pathomorphologic effects of endotoxin in a porcine acute lung injury model. Shock 1998;9(04):274-281 
90 Wang L, Brown JR, Varki A, Esko JD. Heparin's anti-inflammatory effects require glucosamine 6-0-sulfation and are mediated by blockade of L- and P-selectins. J Clin Invest 2002;110(01): 127-136

91 Manfredi AA, Rovere-Querini P, D’Angelo A, Maugeri N. Low molecular weight heparins prevent the induction of autophagy of activated neutrophils and the formation of neutrophil extracellular traps. Pharmacol Res 2017;123:146-156

92 Wan MX, Zhang XW, Törkvist L, Thorlacius H. Low molecular weight heparin inhibits tumor necrosis factor alpha-induced leukocyte rolling. Inflamm Res 2001;50(12):581-584

93 Mulloy B, Hogwood J, Gray E, Lever R, Page CP. Pharmacology of heparin and related drugs. Pharmacol Rev 2016;68(01):76-141

94 Beun R, Kusadasi N, Sikma M, Westerink J, Huisman A. Thromboembolic events and apparent heparin resistance in patients infected with SARS-CoV-2. Int J Lab Hematol 2020;42 (Suppl 1):19-20

95 Mousa SA. Heparin and low molecular weight heparin in thrombosis and inflammation: emerging link. In: Garg HG, Linhardt RJ, Hales CAeds.. Chemistry and Biology of Heparin and Heparan Sulfate. New York, NY: Elsevier Ltd; 2005:571-581

96 Fareed J, Jeske W, Fareed D et al. Are all low molecular weight heparins equivalent in the management of venous thromboembolism? Clin Appl Thromb Hemost 2008;14(04):385-392

97 Gerotziafas GT, Petropoulou AD, Verdy E, Samama MM, Elalamy I. Effect of the anti-factor Xa and anti-factor Ila activities of lowmolecular-weight heparins upon the phases of thrombin generation. J Thromb Haemost 2007;5(05):955-962

98 Salta S, Papageorgiou L, Larsen AK et al. Comparison of antithrombin-dependent and direct inhibitors of factor Xa or thrombin on the kinetics and qualitative characteristics of blood clots. Res Pract Thromb Haemost 2018;2(04):696-707

99 Panigada M, Bottino N, Tagliabue P et al. Hypercoagulability of COVID-19 patients in intensive care unit: A report of thromboelastography findings and other parameters of hemostasis. J Thromb Haemost 2020;18(07):1738-1742

100 Hohlfelder B, Kelly D, Hoang M et al. Activated clotting times demonstrate weak correlation with heparin dosing in adult extracorporeal membrane oxygenation. Am J Ther 2019. Doi: 10.1097/MJT.0000000000001113

101 McLaughlin K, Rimsans J, Sylvester KW et al. Evaluation of antifactor-Xa heparin assay and activated partial thromboplastin time values in patients on therapeutic continuous infusion unfractionated heparin therapy. Clin Appl Thromb Hemost 2019. Doi: $10.1177 / 1076029619876030$

102 Projean D, Lalonde S, Morin J et al. Study of the bioaccumulation of tinzaparin in renally impaired patients when given at prophylactic doses - the STRIP study. Thromb Res 2019;174:48-50

103 Olie RH, Meertens NEL, Henskens YMC, Ten Cate H. Empirically reduced dosages of tinzaparin in patients with moderate-tosevere renal insufficiency lead to inadequate anti-Xa levels. Nephron 2017;137(02):113-123

104 Atiq F, van den Bemt PM, Leebeek FW, van Gelder T, Versmissen J. A systematic review on the accumulation of prophylactic dosages of low-molecular-weight heparins (LMWHs) in patients with renal insufficiency. Eur J Clin Pharmacol 2015;71(08): 921-929

105 Spyropoulos AC, Ageno W, Albers GWet alMARINER Investigators. Rivaroxaban for thromboprophylaxis after hospitalization for medical illness. N Engl J Med 2018;379(12):1118-1127

106 Cohen AT, Spiro TE, Büller HRet alMAGELLAN Investigators. Rivaroxaban for thromboprophylaxis in acutely ill medical patients. N Engl J Med 2013;368(06):513-523

107 Cohen AT, Harrington RA, Goldhaber SZet alAPEX Investigators. Extended thromboprophylaxis with betrixaban in acutely ill medical patients. N Engl J Med 2016;375(06):534-544

108 Ufer M. Comparative efficacy and safety of the novel oral anticoagulants dabigatran, rivaroxaban and apixaban in preclinical and clinical development. Thromb Haemost 2010;103(03): 572-585

109 Glatthaar-Saalmüller B, Mair KH, Saalmüller A. Antiviral activity of aspirin against RNA viruses of the respiratory tract-an in vitro study. Influenza Other Respir Viruses 2017;11(01):85-92

110 Wang Y, Zhong M, Wang Z, Song J, Wu W, Zhu D. The preventive effect of antiplatelet therapy in acute respiratory distress syndrome: a meta-analysis. Crit Care 2018;22(01):60

111 Jin W, Chuang CC, Jin H, Ye J, Kandaswamy E, Wang L, Zuo L. Effects of pre-hospital antiplatelet therapy on the incidence of ARDS. Respir Care 2020;65(07):1039-1045

112 Viecca M, Radovanovic D, Forleo GB, Santus P. Enhanced platelet inhibition treatment improves hypoxemia in patients with severe Covid-19 and hypercoagulability. A case control, proof of concept study. Pharmacol Res 2020;158:104950

113 de Vries AAF. Renin-angiotensin system inhibition in COVID-19 patients. Neth Heart J 2020;28(7-8):396-405

114 Zhang X, Li S, Niu S. ACE2 and COVID-19 and the resulting ARDS. Postgrad Med J 2020;96(1137):403-407

115 Khera R, Clark C, Lu Y et al. Association of angiotensin-converting enzyme inhibitors and angiotensin receptor blockers with the risk of hospitalization and death in hypertensive patients with coronavirus disease-19. medRxiv. Doi: 10.1101/2020.05.17.20104943

116 Felice C, Nardin C, Di Tanna GL et al. Use of RAAS inhibitors and risk of clinical deterioration in COVID-19: results from an Italian cohort of 133 hypertensives. Am J Hypertens 2020;33(10): 944-948

117 Cromwell WC, Otvos JD. Low-density lipoprotein particle number and risk for cardiovascular disease. Curr Atheroscler Rep 2004;6(05):381-387

118 Pirillo A, Bonacina F, Norata GD, Catapano AL. The interplay of lipids, lipoproteins, and immunity in atherosclerosis. Curr Atheroscler Rep 2018;20(03):12

119 Milos S, Hiansen JQ, Banaschewski B et al. The effect of dietinduced serum hypercholesterolemia on the surfactant system and the development of lung injury. Biochem Biophys Rep 2016; 7:180-187

120 Wang H, Yuan Z, Pavel MA, Hansen SB. The role of high cholesterol in age-related COVID19 lethality, Version 3. bioRxiv. Doi: 10.1101/2020.05.09.086249

121 Cao X, Yin R, Albrecht H, Fan D, Tan W. Cholesterol: A new game player accelerating vasculopathy caused by SARS-CoV-2? Am J Physiol Endocrinol Metab 2020;319(01):E197-E202

122 Reiner Ž, Hatamipour M, Banach M et al. Statins and the COVID19 main protease: in silico evidence on direct interaction. Arch Med Sci 2020;16(03):490-496

123 Lee KCH, Sewa DW, Phua GC. Potential role of statins in COVID19. Int J Infect Dis 2020;96:615-617

124 Horby P, Lim WS, Emberson JRet alRECOVERY Collaborative Group. Dexamethasone in hospitalized patients with Covid-19 - preliminary report. N Engl J Med 2020. Doi: 10.1056/NEJMoa2021436

125 Itkonen MK, Tornio A, Lapatto-Reiniluoto O et al. Clopidogrel increases dasabuvir exposure with or without ritonavir, and ritonavir inhibits the bioactivation of clopidogrel. Clin Pharmacol Ther 2019;105(01):219-228

126 Marsousi N, Daali Y, Fontana P et al. Impact of boosted antiretroviral therapy on the pharmacokinetics and efficacy of clopidogrel and prasugrel active metabolites. Clin Pharmacokinet 2018;57(10):1347-1354

127 Testa S, Prandoni P, Paoletti O et al. Direct oral anticoagulant plasma levels' striking increase in severe COVID-19 respiratory syndrome patients treated with antiviral agents: the Cremona experience. J Thromb Haemost 2020;18(06): 1320-1323

128 Langer F, Kluge S, Klamroth R, Oldenburg J. Coagulopathy in COVID-19 and its implication for safe and efficacious thromboprophylaxis. Hamostaseologie 2020;40(03):264-269 
129 Al-Ani F, Chehade S, Lazo-Langner A. Thrombosis risk associated with COVID-19 infection. A scoping review. Thromb Res 2020; 192:152-160

130 Liu X, Zhang R, He G. Hematological findings in coronavirus disease 2019: indications of progression of disease. Ann Hematol 2020;99(07):1421-1428

131 Zhang L, Yan X, Fan Q et al. D-dimer levels on admission to predict in-hospital mortality in patients with Covid-19. J Thromb Haemost 2020;18(06):1324-1329

132 Gris JC, Quéré I, Pérez-Martin A, Lefrant JY, Sotto A. Uncertainties on the prognostic value of D-dimers in COVID-19 patients. J Thromb Haemost 2020;18(08):2066-2067

133 Zhang L. Response to "uncertainties on the prognostic value of Ddimers in COVID-19 patients". J Thromb Haemost 2020;18(08): 2067-2068

134 Zhou F, Yu T, Du R et al. Clinical course and risk factors for mortality of adult inpatients with COVID-19 in Wuhan, China: a retrospective cohort study. Lancet 2020;395(10229):1054-1062

135 Wang D, Hu B, Hu C et al. Clinical characteristics of 138 hospitalized patients with 2019 novel coronavirus-infected pneumonia in Wuhan, China. JAMA 2020;323(11):1061-1069

136 Krupinski J, Catena E, Miguel M et al. D-dimer local expression is increased in symptomatic patients undergoing carotid endarterectomy. Int J Cardiol 2007;116(02):174-179

137 Di Castelnuovo A, Agnoli C, de Curtis A et al. Elevated levels of Ddimers increase the risk of ischaemic and haemorrhagic stroke. Findings from the EPICOR Study. Thromb Haemost 2014;112 (05):941-946

138 Wada H, Trachil J, Di Nisio Met alThe Scientific Standardization Committee on DIC of the International Society on Thrombosis Haemostasis. Guidance for diagnosis and treatment of DIC from harmonization of the recommendations from three guidelines. J Thromb Haemost 2013;11:761-767

139 Tang N, Li D, Wang X, Sun Z. Abnormal coagulation parameters are associated with poor prognosis in patients with novel coronavirus pneumonia. J Thromb Haemost 2020;18(04): 844-847

140 Papageorgiou C, Jourdi G, Adjambri E et al. Disseminated intravascular coagulation: an update on pathogenesis, diagnosis, and therapeutic strategies. Clin Appl Thromb Hemost 2018;24 (9_suppl):8S-28S

141 Levy JH, Sniecinski RM, Welsby IJ, Levi M. Antithrombin: antiinflammatory properties and clinical applications. Thromb Haemost 2016;115(04):712-728

142 Taylor FB Jr, Toh CH, Hoots WK, Wada H, Levi MScientific Subcommittee on Disseminated Intravascular Coagulation (DIC) of the International Society on Thrombosis and Haemostasis (ISTH). Towards definition, clinical and laboratory criteria, and a scoring system for disseminated intravascular coagulation. Thromb Haemost 2001;86(05):1327-1330

$143 \mathrm{Wu}$ C, Chen X, Cai Y et al. Risk factors associated with acute respiratory distress syndrome and death in patients with coronavirus disease 2019 pneumonia in Wuhan, China. JAMA Intern Med 2020;180(07):1-11

144 Fogarty H, Townsend L, Ni Cheallaigh C et al. COVID19 coagulopathy in Caucasian patients. Br J Haematol 2020;189(06): 1044-1049

145 Deng Y, Liu W, Liu K et al. Clinical characteristics of fatal and recovered cases of coronavirus disease 2019 in Wuhan, China: a retrospective study. Chin Med J (Engl) 2020;133(11):1261-1267

146 Gerotziafas GT, Sergentanis TN, Voiriot G et al. Derivation and validation of a predictive score for disease worsening in patients with COVID-19. Thromb Haemost 2020;120(12):1680-1690

147 Levi M, Thachil J, Iba T, Levy JH. Coagulation abnormalities and thrombosis in patients with COVID-19. Lancet Haematol 2020;7 (06): e438-e440

148 Thachil J, Tang N, Gando S et al. Laboratory haemostasis monitoring in COVID-19. J Thromb Haemost 2020;18(08):2058-2060
149 Tang N, Bai H, Chen X et al. Abnormal coagulation parameters are associated with poor prognosis in patients with novel coronavirus pneumonia. J Thromb Haemost 2020;18:844-847

150 Paranjpe I, Fuster V, Lala A et al. Association of treatment dose anticoagulation with in-hospital survival among hospitalized patients with COVID-19. J Am Coll Cardiol 2020;76(01):122-124

151 Ayerbe L, Risco C, Ayis S. The association between treatment with heparin and survival in patients with Covid-19. J Thromb Thrombolysis 2020;50(02):298-301

152 Harenberg J, Favaloro E. COVID-19: progression of disease and intravascular coagulation - present status and future perspectives. Clin Chem Lab Med 2020;58(07):1029-1036

153 Connors JM, Levy JH. COVID-19 and its implications for thrombosis and anticoagulation. Blood 2020;135(23):2033-2040

154 Warren BL, Eid A, Singer Pet al;KyberSept Trial Study Group. Caring for the critically ill patient. High-dose antithrombin III in severe sepsis: a randomized controlled trial. JAMA 2001;286 (15):1869-1878

155 Ranucci M, Ballotta A, Di Dedda U et al. The procoagulant pattern of patients with COVID-19 acute respiratory distress syndrome. J Thromb Haemost 2020;18(07):1747-1751

156 White D, MacDonald S, Bull T et al. Heparin resistance in COVID19 patients in the intensive care unit. J Thromb Thrombolysis 2020;50(02):287-291

157 Wang J, Hajizadeh N, Moore EE et al. Tissue plasminogen activator (tPA) treatment for COVID-19 associated acute respiratory distress syndrome (ARDS): a case series. J Thromb Haemost 2020;18(07):1752-1755

158 Barrett CD, Oren-Grinberg A, Chao E et al. Rescue therapy for severe COVID-19 associated acute respiratory distress syndrome (ARDS) with tissue plasminogen activator (tPA): a case series. J Trauma Acute Care Surg 2020;89(03):453-457

159 Christie DB III, Nemec HM, Scott AM et al. Early outcomes with utilization of tissue plasminogen activator in COVID-19 associated respiratory distress: a series of five cases. J Trauma Acute Care Surg 2020;89(03):448-452

160 WHO. Clinical management of severe acute respiratory infection (SARI) when COVID-19 disease is suspected: interim guidance, 13 March 2020 Accessed July 26, 2020 at: https://apps.who.int/ iris/handle/10665/331446?locale-attribute $=$ fr\&

161 Zhai Z, Li C, Chen Yet al;Prevention Treatment of VTE Associated with COVID-19 Infection Consensus Statement Group. Prevention and treatment of venous thromboembolism associated with coronavirus disease 2019 infection: a consensus statement before guidelines. Thromb Haemost 2020;120(06):937-948

162 Spyropoulos AC, Levy JH, Ageno Wet al;Subcommittee on Perioperative, Critical Care Thrombosis, Haemostasis of the Scientific, Standardization Committee of the International Society on Thrombosis, Haemostasis+. Scientific and Standardization Committee Communication: clinical guidance on the diagnosis, prevention and treatment of venous thromboembolism in hospitalized patients with COVID-19. J Thromb Haemost 2020;18 (08):1859-1865

163 Moores LK, Tritschler T, Brosnahan S et al. Prevention, diagnosis, and treatment of VTE in patients with coronavirus disease 2019: CHEST guideline and expert panel report. Chest 2020;158(03): 1143-1163

164 Thachil J, Tang N, Gando S et al. ISTH interim guidance on recognition and management of coagulopathy in COVID-19. J Thromb Haemost 2020;18(05):1023-1026

165 Barnes GD, Burnett A, Allen A et al. Thromboembolism and anticoagulant therapy during the COVID-19 pandemic: interim clinical guidance from the anticoagulation forum. J Thromb Thrombolysis 2020;50(01):72-81

166 Watson RA, Johnson DM, Dharia RN, Merli GJ, Doherty JU. Anticoagulant and anti-platelet therapy in the COVID-19 patient: a best practices quality initiative across a large health system. Hosp Pract (1995) 2020;48(04):169-179 
167 Kollias A, Kyriakoulis KG, Dimakakos E, Poulakou G, Stergiou GS Syrigos K. Thromboembolic risk and anticoagulant therapy in COVID-19 patients: emerging evidence and call for action. $\mathrm{Br} \mathrm{J}$ Haematol 2020;189(05):846-847

168 Kahn SR, Lim W, Dunn AS et al. Prevention of VTE in nonsurgical patients: antithrombotic therapy and prevention of thrombosis, 9th ed: American College of Chest Physicians evidence-based clinical practice guidelines. Chest 2012;14(2 Suppl):e195S-e226S

169 Nicolaides AN, Fareed J, Kakkar AK et al. Prevention and treatment of venous thromboembolism-international consensus statement. Int Angiol 2013;32(02):111-260

170 Llitjos JF, Leclerc M, Chochois C et al. High incidence of venous thromboembolic events in anticoagulated severe COVID-19 patients. J Thromb Haemost 2020;18(07):1743-1746

171 Helms J, Tacquard C, Severac Fet al;CRICS TRIGGERSEP Group (Clinical Research in Intensive Care and Sepsis Trial Group for Global Evaluation and Research in Sepsis). High risk of thrombosis in patients with severe SARS-CoV-2 infection: a multicenter prospective cohort study. Intensive Care Med 2020;46(06): 1089-1098

172 Leonard-Lorant I, Delabranche X, Severac F et al. Acute pulmonary embolism in COVID-19 patients on CT angiography and relationship to D-dimer levels. Radiology 2020;296(03):E189-E191

173 Grillet F, BehrJ, Calame P, Aubry S, Delabrousse E. Acute pulmonary embolism associated with COVID-19 pneumonia detected by pulmonary CT angiography. Radiology 2020;296(03):E186-E188

174 Middeldorp S, Coppens M, van Haaps TF et al. Incidence of venous thromboembolism in hospitalized patients with COVID-19. J Thromb Haemost 2020;18(08):1995-2002

175 Artifoni M, Danic G, Gautier G et al. Systematic assessment of venous thromboembolism in COVID-19 patients receiving thromboprophylaxis: incidence and role of D-dimer as predictive factors. J Thromb Thrombolysis 2020;50(01):211-216

176 Al-Samkari H, Karp Leaf RS, Dzik WH et al. COVID-19 and coagulation: bleeding and thrombotic manifestations of SARSCoV-2 infection. Blood 2020;136(04):489-500

177 Samama MM, Cohen AT, Darmon JYet al;Prophylaxis in Medical Patients with Enoxaparin Study Group. A comparison of enoxaparin with placebo for the prevention of venous thromboembolism in acutely ill medical patients. N Engl J Med 1999;341 (11):793-800

178 Leizorovicz A, Cohen AT, Turpie AGG, Olsson CG, Vaitkus PT, Goldhaber SZPREVENT Medical Thromboprophylaxis Study Group. Randomized, placebo-controlled trial of dalteparin for the prevention of venous thromboembolism in acutely ill medical patients. Circulation 2004;110(07):874-879

179 Cohen AT, Davidson BL, Gallus ASet al;ARTEMIS Investigators. Efficacy and safety of fondaparinux for the prevention of venous thromboembolism in older acute medical patients: randomised placebo controlled trial. BMJ 2006;332(7537):325-329
180 Violi F, Pastori D, Cangemi R, Pignatelli P, Loffredo L. Hypercoagulation and antithrombotic treatment in coronavirus 2019: a new challenge. Thromb Haemost 2020;120(06):949-956

181 ClinicalTrials.org. Available at: https://clinicaltrials.gov/ct2/results? cond $=$ Covid19\&term $=$ LMWH\&cntry $=\&$ state $=\&$ city $=\&$ dist $=$. Accessed July 26, 2020 at:

182 Gerotziafas GT, Papageorgiou L, Salta S, Nikolopoulou K, Elalamy I. Updated clinical models for VTE prediction in hospitalized medical patients. Thromb Res 2018;164(Suppl 1):S62-S69

183 Hull RD, Schellong SM, Tapson VFet al;EXCLAIM (Extended Prophylaxis for Venous ThromboEmbolism in Acutely Ill Medical Patients With Prolonged Immobilization) study. Extended-duration venous thromboembolism prophylaxis in acutely ill medical patients with recently reduced mobility: a randomized trial. Ann Intern Med 2010;153(01):8-18

184 Laskier V, Guy H, Fisher M et al. Effectiveness and safety of betrixaban extended prophylaxis for venous thromboembolism compared with standard-duration prophylaxis intervention in acute medically ill patients: a systematic literature review and network meta-analysis. J Med Econ 2019;22(10):1063-1072

185 Spyropoulos AC, Anderson FA Jr, FitzGerald Get alIMPROVE Investigators. Predictive and associative models to identify hospitalized medical patients at risk for VTE. Chest 2011;140 (03):706-714

186 Spyropoulos AC, Lipardi C, Xu J et al. Modified IMPROVE VTE risk score and elevated D-dimer identify a high venous thromboembolism risk in acutely ill medical population for extended thromboprophylaxis. TH Open 2020;4(01):e59-e65

187 Rosenberg D, Eichorn A, Alarcon M, McCullagh L, McGinn T, Spyropoulos AC. External validation of the risk assessment model of the International Medical Prevention Registry on Venous Thromboembolism (IMPROVE) for medical patients in a tertiary health system. J Am Heart Assoc 2014;3(06):e001152

188 Cohoon KP, De Sanctis Y, Haskell L, McBane RD, Spiro TE. Rivaroxaban for thromboprophylaxis among patients recently hospitalized for acute infectious diseases: a subgroup analysis of the MAGELLAN study. J Thromb Haemost 2018;16(07): $1278-1287$

189 Schünemann HJ, Cushman M, Burnett AE et al. American Society of Hematology 2018 guidelines for management of venous thromboembolism: prophylaxis for hospitalized and nonhospitalized medical patients. Blood Adv 2018;2(22):3198-3225

190 Bikdeli B, Madhavan MV, Gupta Aet al;Global COVID-19 Thrombosis Collaborative Group. Pharmacological agents targeting thromboinflammation in COVID-19: review and implications for future research. Thromb Haemost 2020; 120(07):1004-1024

191 Guan WJ, Ni ZY, Hu Yet al;China Medical Treatment Expert Group for Covid-19. Clinical characteristics of coronavirus disease 2019 in China. N Engl J Med 2020;382(18):1708-1720 